Portland State University

PDXScholar

\title{
Theoretical and experimental evaluation of hysteresis in atmospheric chemistry
}

Theodore Alan Haigh

Portland State University

Follow this and additional works at: https://pdxscholar.library.pdx.edu/open_access_etds

Part of the Environmental Chemistry Commons

Let us know how access to this document benefits you.

\section{Recommended Citation}

Haigh, Theodore Alan, "Theoretical and experimental evaluation of hysteresis in atmospheric chemistry" (1992). Dissertations and Theses. Paper 4318.

https://doi.org/10.15760/etd.6202

This Thesis is brought to you for free and open access. It has been accepted for inclusion in Dissertations and Theses by an authorized administrator of PDXScholar. Please contact us if we can make this document more accessible: pdxscholar@pdx.edu. 
AN ABSTRACT OF THE THESIS OF Theodore Alan Haigh for the Master of Science in Chemistry presented February 14, 1992.

Title: Theoretical and Experimental Evaluation of Hysteresis in Atmospheric Chemistry.

APPROVED BY THE MEMBERS OF THE THESIS COMMITTEE:
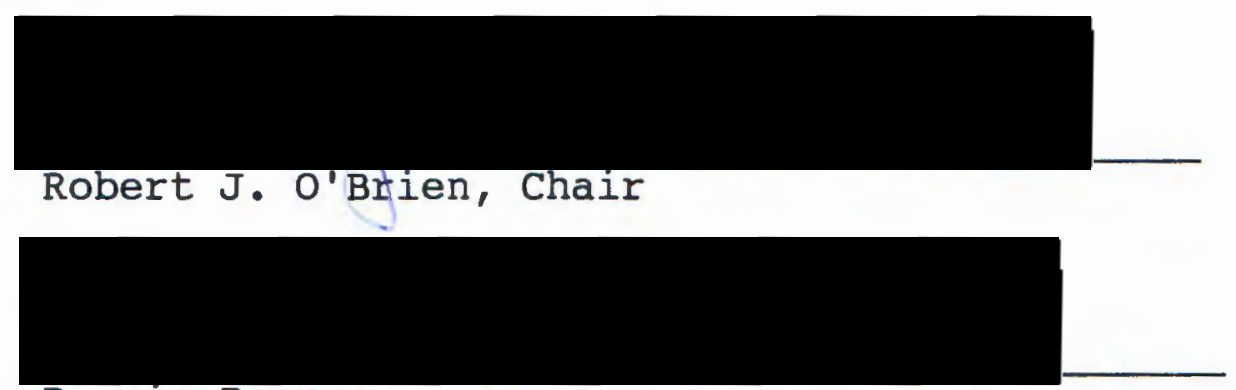

Dennis Barnum
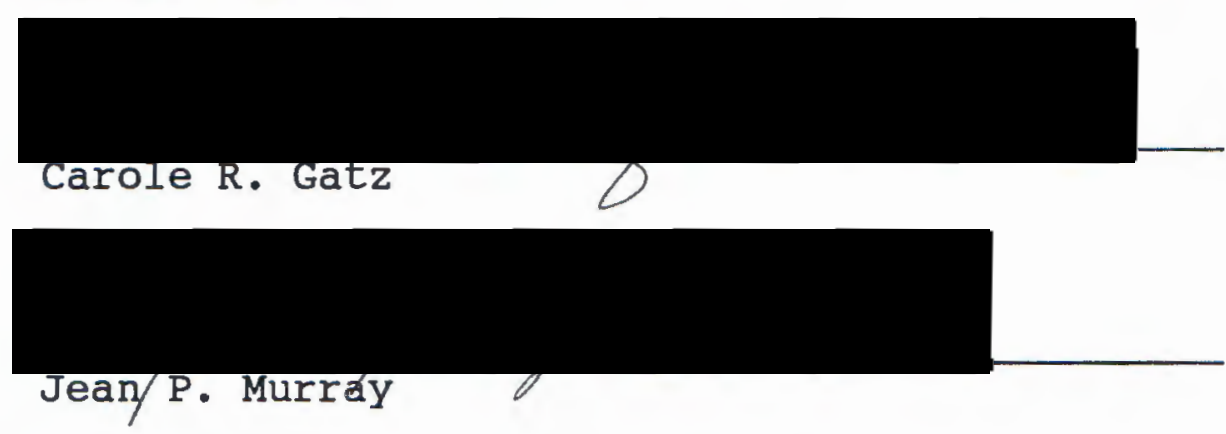

This treatise is a recapitulation of the theoretical and experimental study of hysteresis in atmospheric kinetics. The original problem arose from a theoretical study of a series of reactions for clean air. Upon evaluation a bistable equilibrium was predicted. The steady-state analysis had delineated a metastable region for 
the set of reactions. This bounded region is the hysteresis that this research project evaluated.

The theoretical aspect of the research was initiated with a series of reactions believed to closely approximate the set of reactions that occur in clean air. The rate constants for the reactions were obtained, and the ensuing mechanism was numerically integrated on a computer. The model was then adjusted so as to generate the hysteresis effect in this study. This model was then moved to the laboratory to determine the plausibility of experimentally generating this hysteresis effect.

The experimental setup consisted of a photochemical reactor with controlled flows of the reactant gasses. Control of the chamber was accomplished with a microcomputer, the computer initiated the gas flows, monitored them, and adjusted them accordingly. The experimental setup was allowed to run long enough to cover the region of the hysteresis, as specified by the model. The experimental part of this research demonstrated evidence of a metastable region as predicted by the model. 
THEORETICAL AND EXPERIMENTAL EVALUATION OF HYSTERESIS IN ATMOSPHERIC CHEMISTRY

by

THEODORE ALAN HAIGH

A thesis submitted in partial fulfillment of the requirements for the degree of

\author{
MASTER OF SCIENCE \\ in \\ CHEMISTRY
}

Portland state University

1992 
TO THE OFFICE OF GRADUATE STUDIES:

The members of the Committee approve the thesis of Theodore Alan Haigh presented February 14, 1992.

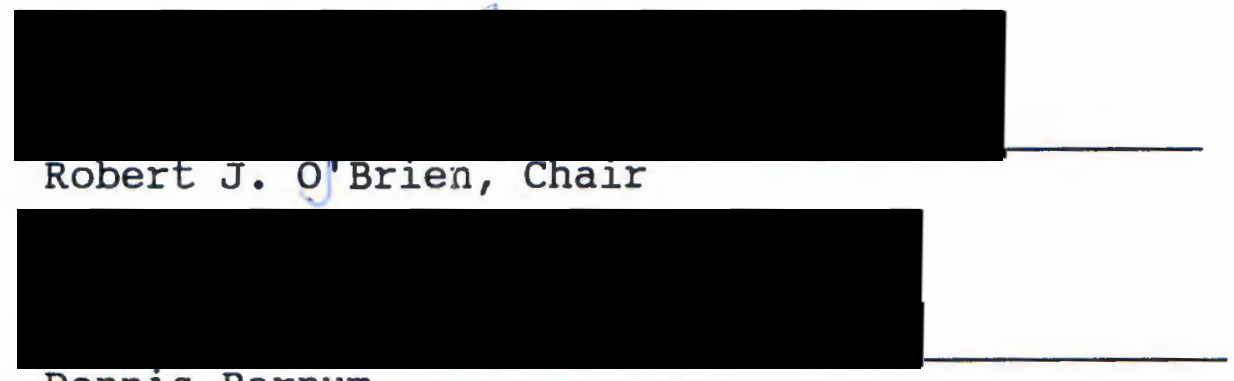

Dennis Barnum

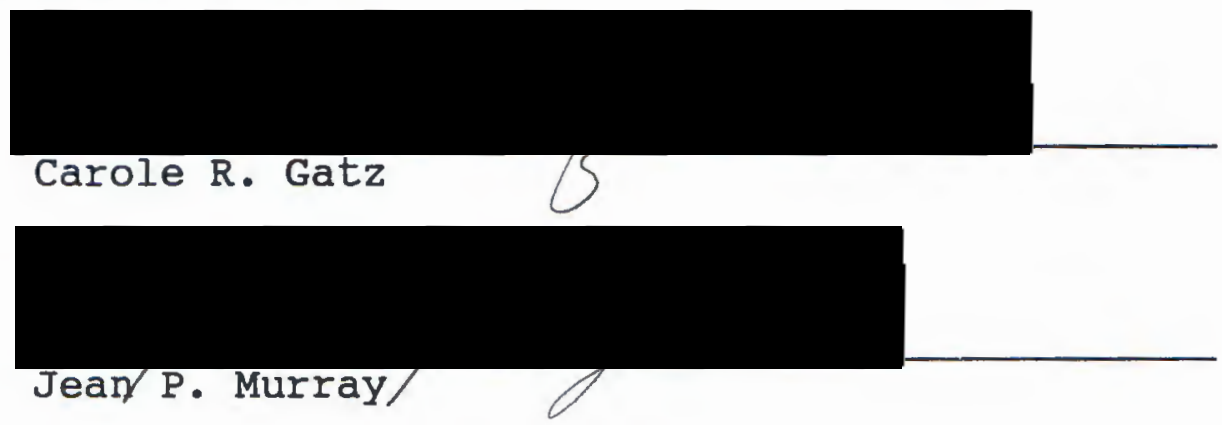

APPROVED :

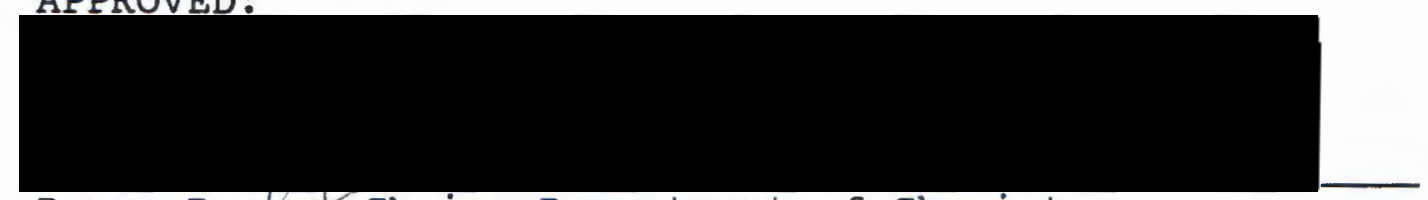

Bruce Brown, Chair, Department of Chemistry

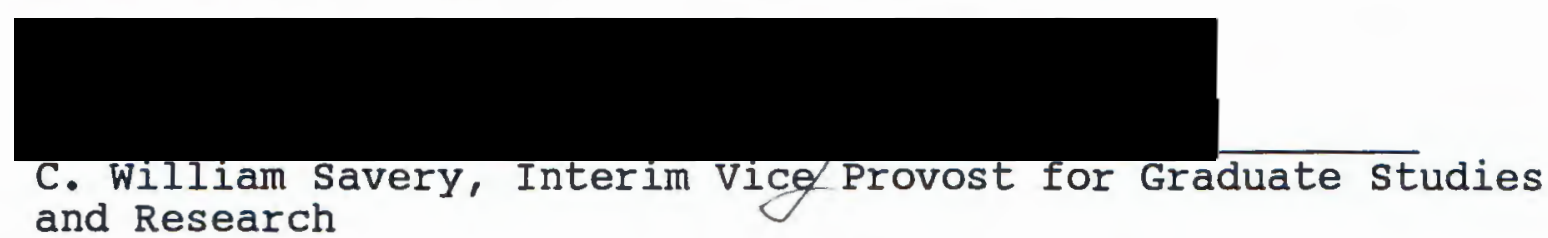


TABLE OF CONTENTS

PAGE

LIST OF TABLES........................ iv

LIST OF FIGURES....................... v

CHAPTER

I INTRODUCTION...................... 1

II DISCUSSION OF HYSTERESIS IN ATMOSPHERIC

CHEMISTRY, PLAUSIBILITY OF HYSTERESIS IN THE

ATMOSPHERE...................... 3

III THEORETICAL STUDY OF HYSTERESIS.......... 8

Chemical Mechanisms.............. 8

Multistability in Flow Reactors...... 8

Modelling of the Mechanisms......... 12

Algebraic Analysis of the Mechanisms.. 13

IV EXPERIMENTAL STUDY OF HYSTERESIS......... 38

Experimental setup.............. 38

Equipment..................... 42

v CONCLUSIONS...................... 52

Theoretical................... 52

Experimental.................. 53

REFERENCES CONSULTED........................ 54

APPENDIX............................. 57 


\section{LIST OF TABLES}

TABLE

PAGE

I Clean Air Mechanism....................... 6

II Clean Air Mechanism used in this Research....... 21

III PAMOL Input file used in modelling the experiment. 22

IV PAMOL Input file for the Clean Air Mechanism in the Reverse Direction......................... 23

V Mathematica Solution for the Clean Air Mechanism.. 24

VI Ten-step Mechanism......................... 26

VII Ten-step Mechanism, Chemistry, and Mathematica solutions..................... 27

VIII Solutions to Elementary Mechanisms and Clean Air Mechanism................................. 28

IX Eleven through Fourteen step Mechanisms......... 29 


\section{LIST OF FIGURES}

FIGURE

PAGE

1 NOx Concentration versus the NO Emission Rate.....

2 Concentration versus Time for Reaction species....

3 Ozone Hysteresis Loop......................

4 Relationship of Hysteresis Loop

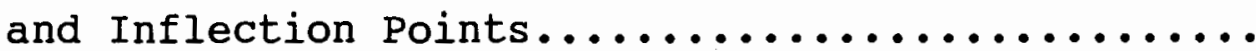

5 Isopleth for the Ten-step Mechanism.

6 Theoretical Isopleth for the Ten-step Mechanism...

7 Isopleth for the Fourteen-Step Mechanism Forward..

8 Isopleth for the Fourteen-step Mechanism Reverse..

9 TKSolver Plot of the Ten-step Solution..........

10 Experimental setup.

11 UltraViolet Absorbance Spectra for Teflon Film.... 45

12 Ozone versus Time from the Initial Bag Test...... 46

13 Ozone and CO Flow versus Time.............. 47

14 Ozone and CO Flow versus Time, Showing Hysteresis. 48

15 Ozone and Co Flow versus Time,

Showing Reproducability.

16 Isopleth for the Clean Air Mechanism Forward..... 50

17 Isopleth for the Clean Air Mechanism Reverse...... 
CHAPTER I

\section{INTRODUCTION}

This treatise is a recapitulation of the theoretical and experimental study of hysteresis in atmospheric kinetics. The original problem arose from a theoretical study of a series of reactions for clean air. Upon evaluation a bistable equilibrium was predicted. The steady-state analysis had delineated a metastable region for the set of reactions. This bounded region is the hysteresis that this research project evaluated.

The theoretical aspect of the research was initiated with a series of reactions believed to closely approximate the set of reactions that occur in clean air. The rate constants for the reactions were obtained, and the ensuing mechanism was numerically integrated on a computer. The model was then adjusted so as to generate the hysteresis effect in this study. This model was then moved to the laboratory to determine the plausibility of experimentally generating this hysteresis effect.

The experimental setup consisted of a photochemical reactor with controlled flows of the reactant gasses. Control of the chamber was accomplished with a micro- 
computer, the computer initiated the gas flows, monitored them, and adjusted them accordingly. The experimental setup was allowed to run long enough to cover the region of the hysteresis, as specified by the model. The experimental part of this research demonstrated evidence of a metastable region as predicted by the model. 
CHAPTER II

\section{DISCUSSION OF HYSTERESIS IN ATMOSPHERIC CHEMISTRY, PLAUSIBILITY OF HYSTERESIS IN THE ATMOSPHERE}

A paper published in Nature (White \& Dietz 1984) proposed that the atmosphere could support multiple equilibrium states. This model was the premise for my research done on hysteresis effects in the atmosphere. The paper in Nature did not address the kinetic consequences of hysteresis, but only the equilibrium states predicted from their model. The model they utilized and the one used for this research are very similar. Both models represent the chemistry of relatively clean air, without the influence of the large concentrations of nonmethane hydrocarbons found in polluted air. The addition of hydrocarbon chemistry is not expected to qualitatively affect the overall results, although it would change the points of equilibrium (London \& Park 1973)(Bufalini et al. 1976)(Altshuller \& McPherson 1967). The model results from White \& Dietz (1984) are shown in Figure 1 and Table 1 shows the mechanism utilized in their study. The figure shows a calculated steady-state $\mathrm{NO}_{x}\left(=\mathrm{NO}+\mathrm{NO}_{2}\right)$ concentration (as crudely simulated for the free troposphere), as a function of the $\mathrm{NO}_{\mathrm{x}}$ source strength. These calculations represent a so-called 
zero-dimensional model, in which instantaneous mixing is assumed and therefore transport of trace gases is ignored. The figure shows a calculated equilibrium contour for $\mathrm{NO}_{x}$ as a function of emissions, and as emissions increase, this path reaches a point where it begins to turn back upon itself. Although white and Dietz did not address the kinetic trajectories along this path, my study finds that at the inflection point the concentration would jump to the upper branch and continue to go up. If emissions were then reduced (for the reverse path) hysteresis behavior is seen. The concentration would follow the upper path (decreasing); then at the left-most inflection point it would fall to the lower branch and continue falling.

The implications of this model could have a dramatic impact on the atmosphere. They imply that if the source rate for No were to continue increasing, it would reach a point at which a small increase in the source would produce an incredible increase in the No concentration. This model also implies that to drop back to some previous initial concentration of NO, the source rate would have to decrease much lower than the source rate just before the jump. This process can be seen in Figure 1. The source rate increases (Path 1), and a large increase in No occurs, then to return to the same initial concentration the source must follow Path 2. This behavior is illustrated for the No concentration, but 
ozone and all other chemical species will show similar discontinuous behavior at the inflection points. Due to the availability of an ozone analyzer for the experimental portion of this thesis, this research has focused on predictions and measurement of the ozone concentration.

The environmental concerns with $\mathrm{NO}_{2}$ and ozone (Clyne 1976), are that they are both physiologically harmful to humans. So local increases in concentration are to be avoided; but globally NO and ozone are necessary to provide the natural balance of cleaning in the atmosphere (Darnall, et al. 1976)(Bufalini, et al. 1976). A balance between the buildup and the destruction must be achieved (Pitts, Lloyd, \& Sprung 1975)(Penkett 1991)(London \& Park 1973).

My research delves into the theoretical and experimental aspects of this effect. The theoretical aspect of this model has borne out that this effect could happen and the parameters for the inflection points have been studied. In order to begin to understand the phenomenon of atmospheric hysteresis, simplistic chemical models have been mathematically studied to determine the points at which discontinuous concentration behavior occurs. 
TABLE I

\section{CLEAN AIR MECHANISM}

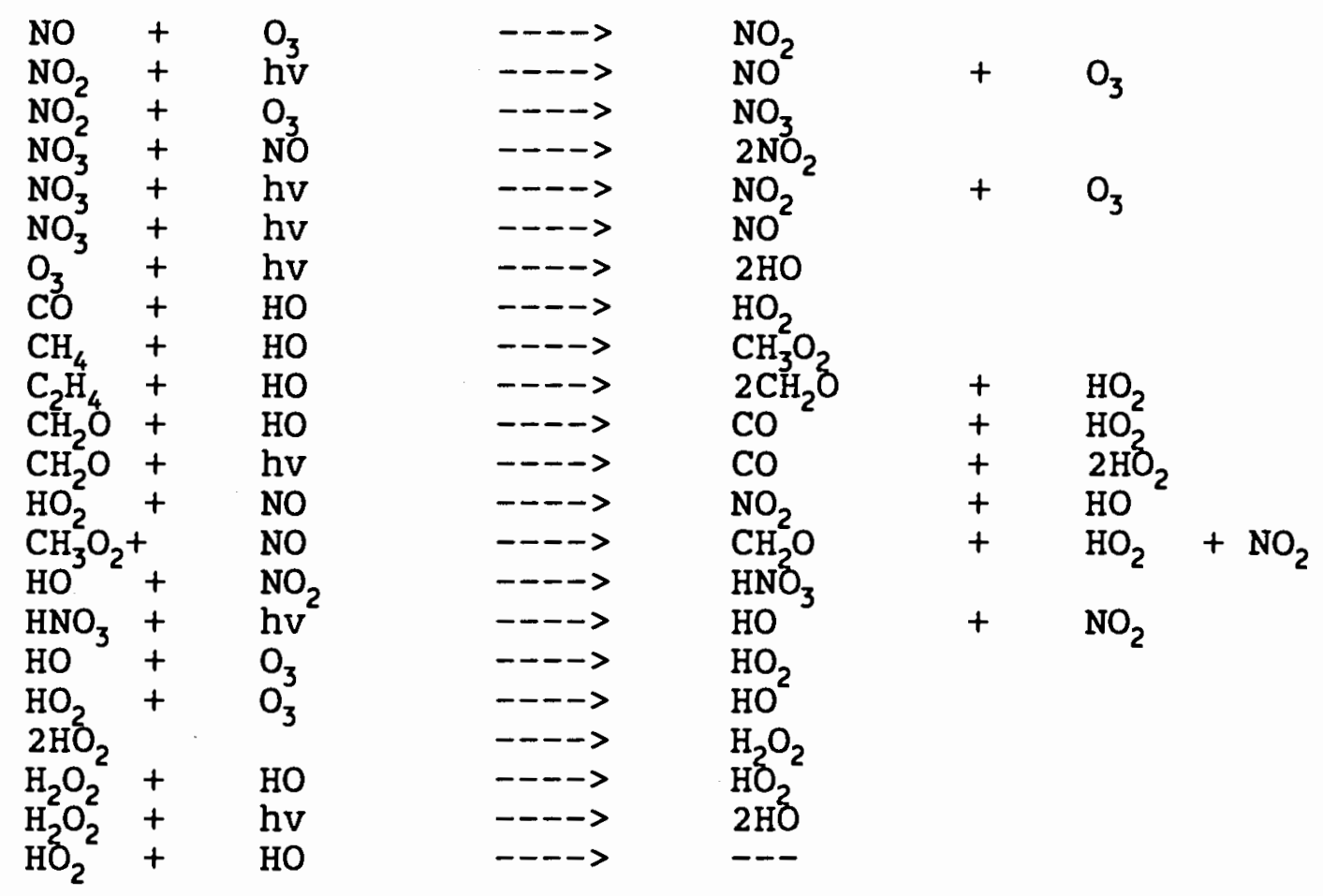

This mechanism provided evidence that the atmosphere could support multiple steady states. From this mechanism, and the others, a more complete model of clean air chemistry was built. 


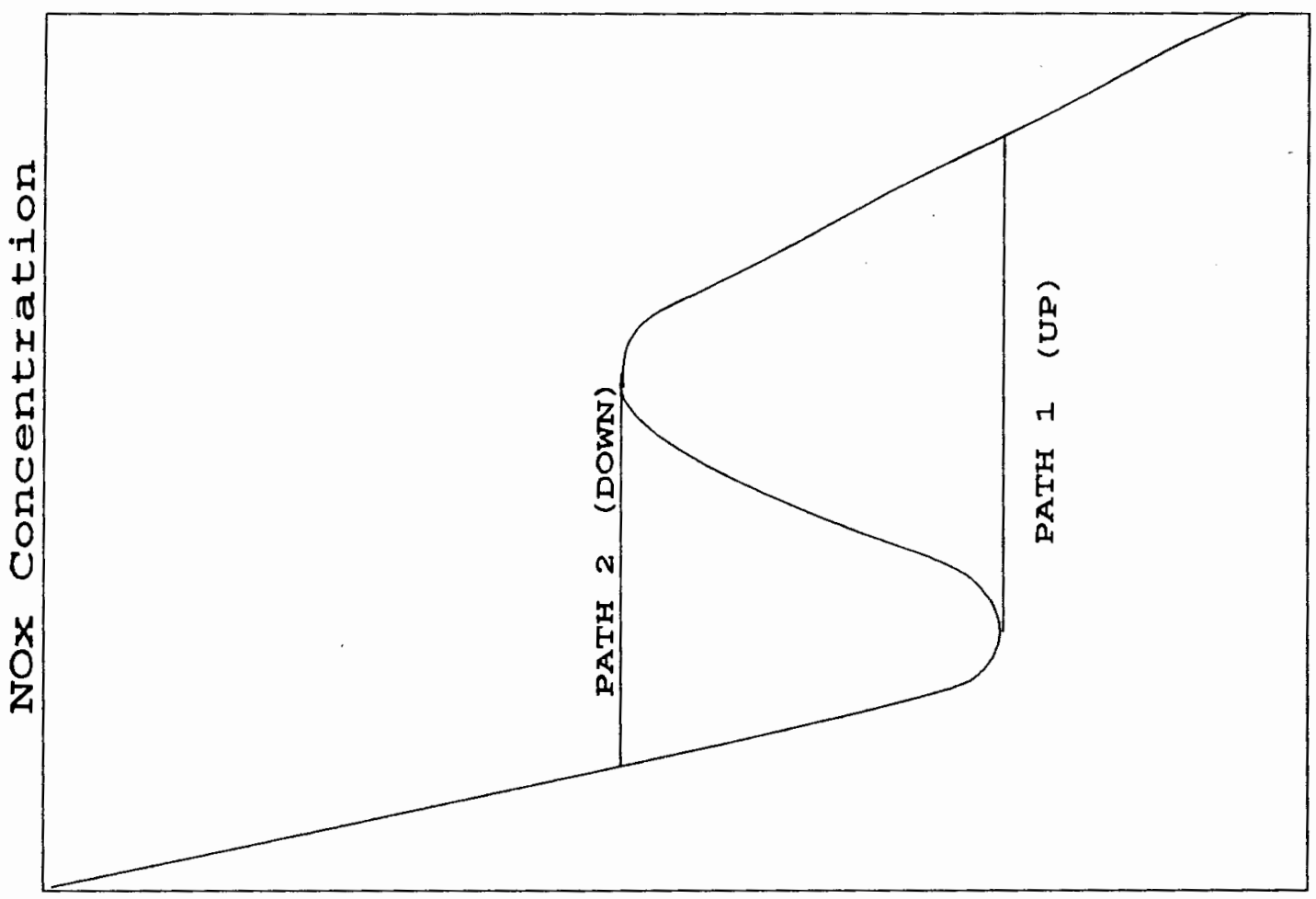

NOX Source

Figure 1. NOx concentration versus the NO emission rate. This figure is adapted from NATURE, (White \& Dietz 1984). This shows the steady state NOx concentration in the free troposphere, as a function of the NOx source rate. The features of this figure show that at certain source rates there are multiple NOx concentrations possible. (Gray \& Scott 1990). 
CHAPTER III

THEORETICAL STUDY OF HYSTERESIS

\section{CHEMICAL MECHANISMS}

Initiation of the study of the hysteresis effect came by compiling a reasonable set of reactions that would approximate the chemistry of the troposphere, as has been experimentally and theoretically verified (Crutzen 1973). The set of reactions initially used are listed in Table II, this set was analyzed and determined to be a mechanism comprehensive enough to account for the chemistry (Koop \& Ogren 1976)(Logan, et al. 1981)(Dietz \& White 1984) that would take place in the experimental analysis. This mechanism was analyzed, see Figure 2, and the hysteresis effect was found to be achieved, see Figure 3 .

\section{MULTISTABILITY IN FLOW REACTORS}

In attempting to understand the hysteresis effect mathematically, it was decided to regress to very simple mechanisms capable of analytical solutions. Ultimately, this knowledge could be applied to the more complex problem. The simplest model for this system is the continuously fed well-stirred reactor, adapted from Gray \& Scott (1990), 
using a simple chemical reaction for cubic autocatalysis:

$$
A+2 B-D \quad 3 B \text { rate }=k_{1} a b^{2}
$$

In the atmosphere or the experiment the following series of reactions would give an overall net reaction for the autocatalysis of ozone:

\begin{tabular}{|c|c|c|c|c|c|c|}
\hline $\mathrm{O}_{3}$ & + & No & $---->$ & $\mathrm{NO}_{2}$ & + & $\mathrm{O}_{2}$ \\
\hline $3 \mathrm{NO}_{2}$ & + & $3 \mathrm{~h} v$ & $---->$ & $30\left(X^{3} P\right)$ & + & $3 \mathrm{NO}$ \\
\hline $30\left(x^{3} P\right)$ & + & $3 \mathrm{O}_{2}$ & $----->$ & $3 \mathrm{O}_{3}$ & & \\
\hline $\mathrm{O}_{3}$ & + & $\mathrm{h} v$ & $----->$ & $O\left(a^{1} D\right)$ & + & $\mathrm{O}_{2}$ \\
\hline$O\left(a^{1} D\right)$ & + & $\mathrm{H}_{2} \mathrm{O}$ & $---->$ & $2 \mathrm{HO}$ & & \\
\hline $2 \mathrm{HO}$ & + & $2 \mathrm{CO}$ & $----->$ & $2 \mathrm{CO}_{2}$ & + & $2 \mathrm{H}$ \\
\hline $2 \mathrm{H}$ & + & $2 \mathrm{O}_{2}$ & $----->$ & $2 \mathrm{HO}_{2}$ & & \\
\hline $2 \mathrm{NO}$ & + & $2 \mathrm{HO}_{2}$ & $---->$ & $2 \mathrm{NO}_{2}$ & + & $2 \mathrm{HO}$ \\
\hline
\end{tabular}

The overall reaction is:

$$
2 \mathrm{O}_{3}+3 \mathrm{O}_{2}+\mathrm{H}_{2} \mathrm{O}+2 \mathrm{CO}------>3 \mathrm{O}_{3}+2 \mathrm{HO}+2 \mathrm{CO}_{2}
$$

The idealized reactor is fed by a stream, or separate streams, of $A$ and $B$ with initial concentrations of $a_{0}$, and $b_{0}$ respectively. The concentrations of the two species in the well-mixed reactor are $a$ and $b$.

The concentration of $A$ is determined by the three 
quantities: the rate of inflow of $A$, the rate of outflow of $A$, and the conversion of $A$ to $B$. Combining these three processes, an expression for the net rate can be expressed in terms of $A$ molecules per second in the reactor.

$$
\mathrm{V} d a / d t=q a_{0}-q a-V k_{1} a b^{2}
$$

Here $\mathrm{qa}_{0}$ is the volume flow rate in times the initial

concentration of $a, q a$ is the volume flow rate out times the concentration of $a$ in the reactor, and the last term is the reaction rate (conversion of $A$ to $B$ ). Since the reaction stoichiometry can be expressed as:

$$
a_{0}+b_{0}=a+b,
$$

then $b$ can be eliminated from the net rate expression to give

$$
d a / d t=k_{\text {flow }}\left(a_{0}-a\right)-k_{1} a\left(a_{0}+b_{0}-a\right)^{2}
$$

where da/dt is the net change in the concentration of $a$, the first term to the right of the equal sign is the net inflow, and the second term is the chemical reaction rate.

This relationship is obtained by dividing the original equation by $v$, and calling the quantity $q / v$ the flow constant $\mathrm{k}_{\text {flow }}\left(\right.$ time $\left.^{-1}\right)$. Note that although the above chemical 
reaction sequence represents an overall stoichiometry whereby ozone is created autocatalytically $\left(2 \mathrm{O}_{3}-->3 \mathrm{O}_{3}\right)$, the complex mechanism does not necessarily have the same reaction order as the cubic autocatalysis model reaction. At reactor steady state, the net inflow of $A$ will eventually be balanced by outflow and chemical reaction. At sufficient reaction time this condition is met and then $\mathrm{da} / \mathrm{dt}=0$. The last expression now becomes:

$$
k_{\text {flow }}\left(a_{0}-a_{s s}\right)-k_{1} a_{s s}\left(a_{0}+b_{0}-a_{s s}\right)^{2}=0
$$

The steady state concentration of a $\left(a_{s s}\right)$ can now be expressed as the roots of the cubic equation, in terms of $k_{\text {flow, }} a_{0}, b_{0}$, and $k_{1}$. Cubic equations can have one or three real roots, and since the quantities involved in the solutions are physical quantities, only the positive solutions are desired. If there is only one positive real root, this corresponds to a unique steady state for the given flow. If the solution involves three positive real roots this will be a region that corresponds to multiple steady states, since all correspond to da/dt=0. A method to visualize the solutions is to generate a set of lines such that one line is defined by the equation $L 1=k_{f l o w}\left(a_{0}-a\right)$ and the other line would be $L 2=k_{1} a\left(a_{0}+b_{0}-a\right)^{2}$. By plotting the two functions versus the extent of the reaction, one may note that each time the two lines cross this corresponds to L1=L2. When this technique produces three intersections 
this corresponds to a point where a given flow rate produces three steady state concentrations of a. In such a case, the upper and lower concentrations represent an equilibrium state of the system, but the middle concentration is unstable with respect to conversion to one of the other two values. Figure 4 (page 32 ) indicates the various possible solutions to these equations.

\section{MODELLING OF THE MECHANISMS}

Kinetic analysis of the mechanisms was accomplished by utilizing an APOLLO DN10000 computer and the program PAMOL to numerically integrate the series of reactions in the mechanism, under the conditions specified in the input file. An input file for the program PAMOL, Table III, included an extensive format that allowed the investigator to adjust parameters of the mechanism to obtain data for varying conditions. The first line in the file contains the error level tolerance, simulation time to print an element of data, and the time to stop the calculation process. The main body of the file includes the reactions, products, and rate coefficients. The matrix at the bottom of the file lists all the species' initial concentrations. The final lines of the file list species that are held constant during the integration process. By processing the file through the program PAMOL, the integration program, the computer 
generates a file of the concentration of each species, at each specified printout time. This analysis was done until the input file generated the hysteresis effect associated with increasing and decreasing emission rates. This output file can then be graphed to observe the changes in concentration versus time. A more useful plot displays species concentration vs. the emission rate as shown in Figure 3. Here, "forward reaction" indicates increasing co emissions $\left(S_{C O}\right)$ and "reverse reaction" indicates decreasing emissions. In both cases the emission rate was changed sufficiently slowly that each point represents an equilibrium state of the system. This was verified by decreasing the emissions increase rate until the behavior converged to that typified by Figure 3 .

\section{ALGEBRAIC ANALYSIS OF THE MECHANISMS}

The mechanism listed above was designed to represent the actual chemistry that would produce a hysteresis effect. Analysis of the kinetic mechanism was done by setting the differential equation for each species to zero, representing an equilibrium state of the system. Algebraic analysis of this large system of second order equations proved to be rather difficult, but a set of simplified solutions is noted in Table IV (page 23). Because of the complexity of this equation set, a determination was made to start with a 
fairly simple mechanism (Beno, et al. 1985), and do a similar analysis to determine if more understandable results could be obtained. The ten step mechanism noted in Table VI was one simple mechanism that would provide a understandable solution to the steady state analysis. This mechanism does indeed show discontinuous behavior of species concentrations, but since there are no removal processes for many species other than Ho reaction, kinetic analysis cannot achieve steady state for some values of emission rates. The ten step mechanisms' solutions to the steady state approximation are listed at the bottom of Table VII. These solutions are listed as equations that have the independent variables, the source rates, on one side of the equation, and the reaction rates on the other. In this particular solution there are combinations of the source rates that could produce negative values for the give reaction rate. A negative value for the rate would have no real meaning, so a set of inequalities, see Table VII, can be formed from the solutions. These inequalities are conditions that define the limits where the rate of the reaction will be positive or zero. The inequalities also define the limits of stability for the system in question, and hence the points of discontinuous species' concentrations.

The larger mechanism that better approximates the chemistry of clean air also shows similar features to the 
ten step mechanism. This similarity leads to the conclusion that there should be a solution that has features in common with the ten step solution. The solution noted for the large mechanism, Table $\mathrm{V}$, is considerably more complex. By rearrangement of the solution in Table $v$, the dependant variables can be expressed in terms of the independents, the source rates. The source rates for this large mechanism expressed in terms of the independent variables are:

$$
\begin{gathered}
S_{03}=R 15+R 16-R 2+R 5+R 6+R 25 \\
S_{\text {NO }}=2(R 12+R 13-R 21-R 9)
\end{gathered}
$$

or (two solutions for $s_{N O}$ were produced)

$$
\begin{gathered}
S_{\mathrm{NO}}=2(\mathrm{R} 12-\mathrm{R} 11-\mathrm{R} 10+\mathrm{R} 13-\mathrm{R} 21) \\
\mathrm{S}_{\mathrm{CO}}=\mathrm{R} 11+\mathrm{R} 17+\mathrm{R} 21-\mathrm{R} 23+\mathrm{R} 30+\mathrm{R} 31+\mathrm{R} 32+\mathrm{R} 33+\mathrm{R} 34-\mathrm{R} 25
\end{gathered}
$$

Since the solutions for $s_{03}, S_{N O}$ and $s_{C O}$ have negative terms (e.g. -R2 in the $s_{03}$ equation above), this introduces another consideration into the interpretation of the solution. Allowing a term to be subtracted allows the source to become negative if the subtracted quantity becomes large enough. With this in mind the actual physical interpretation of the combination of the source rates becomes clouded. The fourteen step mechanism was the first of the smaller models to show this similar feature, that model as well as this larger one did express the hysteresis effect.

Table VIII shows the solutions to various mechanisms 
from a ten step to a fourteen step, the last entry is the similar solution for the large clean air mechanism. The solutions to all subsequent mechanisms have been arranged to generate similar results that produce the same relationships between the independent variables. As noted before, only the very simplistic mechanisms provide a relationship between the dependent, and independent variables that have only additive terms for the dependant variables. This leads to a series of inequalities that define the regions that have any physical meaning. Similar inequalities can be had for the solutions that do not have such a straight forward interpretation. The fourteen step mechanism would now have two inequalities for each combination of independent variables, Table IX.

To get a better understanding of the behavior of the solutions to the mechanisms, the one-variable analysis illustrated by Figure 3 was expanded to two dimensions with two source rates serving as independent variables with the third held constant. For this analysis the PAMOL program was used to generate isopleth plots of steady-state concentrations reached at long integration times. In this operational mode, PAMOL uses a similar input format for the time-based integration. In this case the pair of source rates are held constant at specified values until convergence of chemical concentrations to equilibrium 
occurs. The convergence criteria is now set by the added line at the top of the input file, e.g. isop=.001. In this case, integration would proceed until all concentrations changed less than $0.1 \%$ between printouts. At this point the program steps to the next emission or source rate value. A sample isopleth diagram is seen in Figure 5. This diagram is like a topographic map, each line is a line of constant concentration, analogous to the contour lines on a map. At the point of inflection there is a piling up of these lines, a cliff. The reaction is run in the reverse direction (decreasing emissions) by reversing the list of values for the sources noted at the bottom of the input file, see Table VI. The point at which the inflection occurs is at a different position relative to the other direction. This displacement of the cliff for the forward and reverse directions delineates the hysteresis region in two dimensions. Using these diagrams it is possible to relate the major features to the solutions. Taking the ten step mechanism, Figure 5, the cliff can be seen in the center of the plot. The $\mathrm{x}$-axis is the ozone source rate $\mathrm{S}_{03}$, and the $\mathrm{y}$-axis is the Nitric Oxide source rate $\mathrm{s}_{\mathrm{NO}}$. The contour lines delineate regions of constant ozone concentration. To understand the features of this three-dimensional cliff in the context of a four dimensional problem $\left(\mathrm{O}_{3}\right.$ concentration vs. $S_{03}, S_{N o}$, and $s_{c 0}$ ) it useful to normalize both axes. This 
is done by dividing the source rates for nitric oxide, and ozone by the constant carbon monoxide source rate used for this calculation, $S_{C 0}=1 \times 10^{-8}$, then take the log of the resulting number. Using the normalized values for the axes, and the solution for the ten-step reaction, Table VIII, some of the features of the cliff can be discerned. The cliff intersects the $\mathrm{y}$-axis at $\log (2)$, this intersection can be explained from the solution to the ten-step mechanism. Normalization of the solution produces the following:

$$
2 \mathrm{~s}_{\mathrm{CO}} / \mathrm{s}_{\mathrm{CO}}+2 \mathrm{~s}_{\mathrm{O} 3} / \mathrm{s}_{\mathrm{CO}}=\mathrm{s}_{\mathrm{NO}} / \mathrm{s}_{\mathrm{CO}}
$$

This equation then reduces to;

$$
2+2 \mathrm{~S}_{03} / \mathrm{S}_{\mathrm{CO}}=\mathrm{S}_{\mathrm{NO}} / \mathrm{S}_{\mathrm{CO}}
$$

Substituting the value for $s_{c o}$ the last equation yields:

$$
2+2 S_{03} / 1 \times 10^{-8}=S_{\mathrm{NO}} / 1 \times 10^{-8}
$$

Reducing the last equation to $x$ and $y$ coordinates it now becomes ;

$$
2+2 \mathrm{x}=\mathrm{y}
$$

From this series of equations it can be seen that when $x<<1$ then $y=2$, or $\log (y)=\log (2)$. If $x>>1$ then $y=2 x$, or $\log (y)=\log (x)+\log (2) . \quad$ The $\log (y)=\log (2)$ is the intersection of the cliff on the $y$-axis, the inflection point at the beginning of the upward slope is at the $S_{c o}$ value. Figure 6 is an isopleth diagram of the solution plotted using the 
values for the source rates that produced Figure 5. Figure 6 used only the solution to the ten-step mechanism to generate the isopleth lines. The procedure for generating this plot was to enter the mechanism into the program that produces the isopleth diagrams, then allow it to use the mechanism and the source rate values to iteratively produce values for the ozone concentration. The features of the two Figures are very similar, noting that the theoretical plot shows no concentrations in the upper left corner. This region is where the concentration would be zero, or negative. Using a similar technique for the analysis of the fourteen step mechanism, many of the same features are seen. The cliff intersects the $y$-axis at $\log (2)$, the inflection point marking the cliff's upward climb is at the $s_{03}$ value of $1 \times 10^{-4}$, see Figure 7. This mechanism has a significant difference from the ten-step mechanism in that it shows a well defined hysteresis region, see Figure 8 . Using the solutions for the ten-step mechanism in Table VII, a cross section of the isopleth is generated. The solution is entered in TKSolver Plus, an equation solving program, and the list of values for the source rates are supplied. The program then will calculate the values for the remaining variables, and the plot is seen in figure 9. The intersections and convergences define the limits of the cliff. The ten-step mechanism did not produce a hysteresis 
region due to the lack of chemical loss processes when the HO concentration is very low. The ten-step mechanism does show a cliff when the source rates are decreased, but if the initial concentrations of all species are started low, when the source rates are increased no cliff is seen. This results from the lack of loss processes, the concentrations of nitric oxide, and carbon monoxide build to high levels, thereby reducing the hydroxyl radicals and ozone to such low levels that the system is far from the metastable hysteresis region. 
TABLE II

CLEAN AIR MECHANISM USED IN THIS RESEARCH

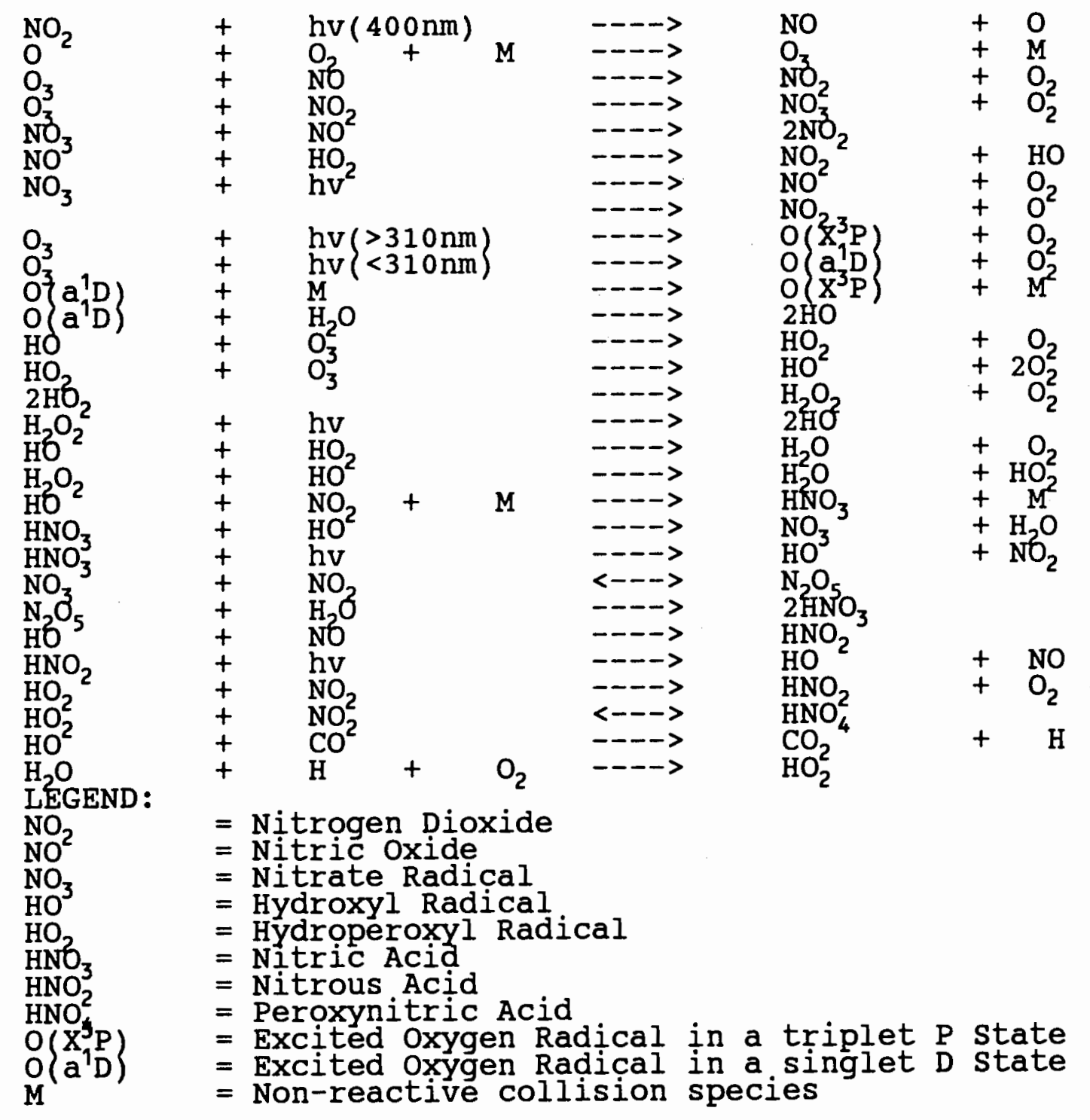


TABLE III

PAMOL INPUT FILE USED IN MODELLING THE EXPERIMENT

* comments*/

$\$$ command Const err $=1 \mathrm{e}-3$ tprnt $=1$ ts tep $=60$ s topp $=7.5 \mathrm{e} 3$ reactionout smallerr $=1 \mathrm{e}-25$ dilute $=0.01$

\section{\$reaction}

$1 \mathrm{NO} 2$
$3 \mathrm{O}$
$3 \mathrm{O}$

40

$5 \mathrm{NO}$

$7 \mathrm{NO}$

$8 \mathrm{NO}$

$9 \mathrm{NO} 2$

$10 \mathrm{~N} 205$

$12 \mathrm{NO} 2$

$13 \mathrm{NO} 3$

$14 \mathrm{NO} 3$

1503

$170 D$

$180 \mathrm{D}$

$19 \mathrm{NO}$

$20 \mathrm{HONO}$

$21 \mathrm{NO} 2$

$22 \mathrm{NO}_{2}$

$23 \mathrm{HNO} 3$

$24 \mathrm{CO}$

2503

$26 \mathrm{NO}$

$27 \mathrm{NO} 2$

$28 \mathrm{HNO} 4$

3003

$31 \mathrm{HO} 2$

$32 \mathrm{HO} 2$

$33 \mathrm{NO}$

$34 \mathrm{NO} 3$

$35 \mathrm{SO} 3$

$36 \mathrm{SNO}$

38 SCO

39 SCO

sinit
$\mathrm{HV}$
NO2
NO2
$\mathrm{O} 3$
$\mathrm{O} 3$
NO3
NO
NO3

NO2O

HV

HV

HV

H2O

HO

$\mathrm{H} 2 \mathrm{O}$

HO

$\mathrm{HO}$

HO

HO2

HO2

HO

$\mathrm{HO}_{2}$

$\mathrm{HO} 2$

$\mathrm{HO} 2$
$\mathrm{HO} 2$

E

t

03

HNO3

HNO 4

HV

OD

SCO

TEMP

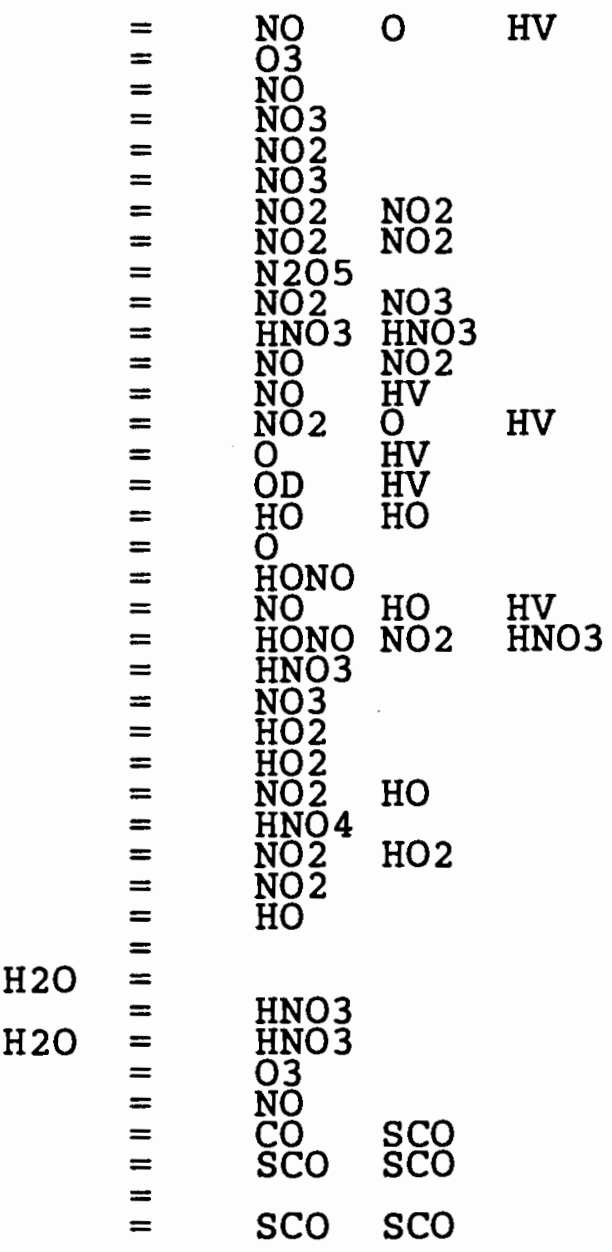

$\begin{array}{lll}4.260 \mathrm{E}-01 & 0 \\ 4: 650 \mathrm{E}+07 & 0 \\ 1.370 \mathrm{E}+04 & 0 \\ 3 & 290 \mathrm{E}+03 & 0 \\ 2 & 680 \mathrm{E}+01 & 0\end{array}$

$2.680 \mathrm{E}+010$

$2.750 \mathrm{OE}+040$

$1.430 \mathrm{E}-040$

$1.710 \mathrm{E}+030$

$2.080 \mathrm{E}+000$

$1.480 \mathrm{E}-060$

5.980E-01

$1.081 \mathrm{E}+00$

$9.287 \mathrm{E}+00$

$2.432 \mathrm{E}-020$

$1.218 \mathrm{E}-030$

$3.250 \mathrm{E}+050$

$4.320 \mathrm{E}+100$

$9.750 E+030$

$8.264 \mathrm{E}-020$

$5.910 \mathrm{E}-090$

$1.680 \mathrm{E}+040$

$1.890 \mathrm{E}+02.0$

$3.220 \mathrm{E}+02$

$1.000 \mathrm{E}+020$

$1.220 \mathrm{E}+040$

$2.020 \mathrm{E}+03$

$4.930 \mathrm{E}+000$

$5.910 \mathrm{E}+030$

$2.960 \mathrm{E}+000$

$4.460 \mathrm{E}+030$

$2.540 \mathrm{E}-010$

$4.460 \mathrm{E}+030$

$2.540 \mathrm{E}-010$

$\begin{array}{ll}1 & 0 \\ 1 & 0 \\ 1 & 0 \\ 80 & 000 \mathrm{E}-00 \\ 0.01 & 0 \\ 0.01 & 0\end{array}$

HONO

E

NO3

N205

$\mathrm{CO} \quad \mathrm{HO} 2$

SNO $\quad \mathrm{SO} 3$

$2.144 \mathrm{E}-08 \quad 8.233 \mathrm{E}-03$

$2.322 \mathrm{E}+00 \quad 4.529 \mathrm{E}+00 \quad 8.810 \mathrm{E}-09 \quad 1.650 \mathrm{E}-05$

$1.592 \mathrm{E}+001.992 \mathrm{E}-13$

$7.472 \mathrm{E}-08$

$4.100 \mathrm{E}-02$

$1.408 \mathrm{E}+01 \quad 6.132 \mathrm{E}-09$

$5.828 \mathrm{E}-06$

$5.628 E-02$

$2.200 E+04$

$7.944 \mathrm{E}-05$

$4.200 E-02$

$1.140 \mathrm{E}-02$

$1.000 \mathrm{E}+00 \quad 2.982 \mathrm{E}+02$

sconst

SO3 SNO E H2O

\$end 
TABLE IV

PAMOL INPUT FILE FOR THE CLEAN AIR MECHANISM IN THE REVERSE DIRECTION

$/$ *omments*/

$\$$ command const err $=1 e-3$ tprnt $=1$. tstep $=60$ stopp $=7.5 e 3$

reactionout smalierr $=1 e-25$ dilute $=0.01$

sreaction

$1 \mathrm{NO} 2$

30

40

$5 \mathrm{NO}$

$6 \mathrm{NO} 2$

$7 \mathrm{NO}$

$8 \mathrm{NO}$

$9 \mathrm{NO} 2$

$10 \mathrm{~N} 2 \mathrm{O} 5$

$11 \mathrm{~N} 205$

$12 \mathrm{NO} 2$

$13 \mathrm{NO} 3$

$14 \mathrm{NO} 3$

1503

1603

$170 \mathrm{D}$

$180 \mathrm{D}$

$19 \mathrm{NO}$

20 HONO

$21 \mathrm{NO} 2$

$22 \mathrm{NO} 2$

$23 \mathrm{HNO} 3$

$24 \mathrm{CO}$

2503

26NO

$27 \mathrm{NO} 2$

$28 \mathrm{HNO} 4$

$29 \mathrm{HNO} 4$

3003

$31 \mathrm{HO} 2$

$32 \mathrm{HO} 2$

$33 \mathrm{NO} 3$

$34 \mathrm{NO} 3$

$35 \mathrm{SO} 3$

36SNO

$37 \mathrm{SCO}$

$38 \mathrm{SCO}$

$39 \mathrm{SCO}$

sinit

$40 \mathrm{SCO}$

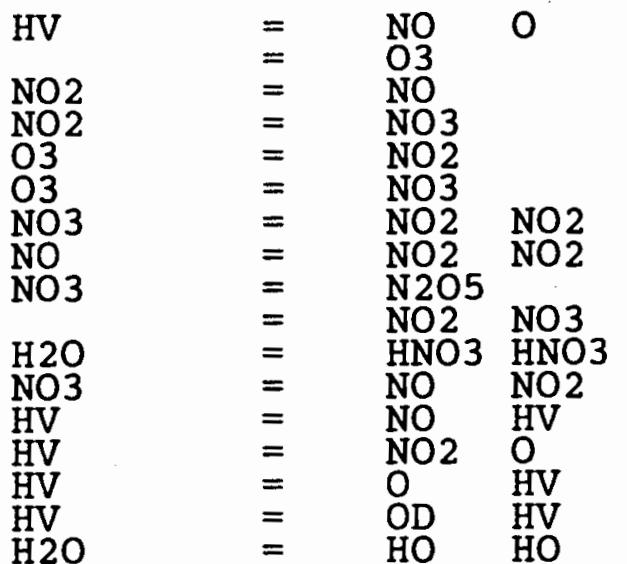

$\mathrm{HO}$

$\mathrm{HO}$

$\mathrm{NO} 2 \mathrm{HO}$

O
HNO3
HNO4

HV

$2.144 \mathrm{E}-08$

$1.592 \mathrm{E}+00$

$1.000 \mathrm{E}+00$

sconst

SO3 SNO E

Send $2.982 \mathrm{E}+02$

E $\mathrm{H} 2 \mathrm{O}$
HV

HO HO

$\mathrm{HO} \quad=$ HONO

HV

$\mathrm{H} 2 \mathrm{O}$

$\mathrm{HO}$

$\mathrm{HO}$

$\mathrm{HO} 2$

$\mathrm{HO} 2$

$\mathrm{HO} 2$

$\mathrm{HO} 2$

$\mathrm{HO} 2$

$\mathrm{HO} 2$

HONO

HONO NO2

HNO3

NO3

$\mathrm{HO} 2$

$\mathrm{HO} 2$

HNO4

$\mathrm{NO} 2 \mathrm{HO} 2$

NO2

HO

$\mathrm{H} 2 \mathrm{O}$

$\mathrm{H} 2 \mathrm{O}$

$=$ HNO3

$\mathrm{HNO}$

NO

$\underset{\mathrm{E}}{\mathrm{E}}$

HV

4. 260E-01 0

4.650E+07 0

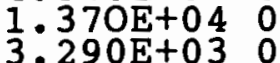

$2.680 E+010$

$4.770 \mathrm{E}-020$

$2.750 \mathrm{E}+040$

$1.430 \mathrm{E}-040$

$1.710 \mathrm{E}+030$

$2.080 \mathrm{E}+000$

$1.480 \mathrm{E}-060$

$5.980 \mathrm{E}-010$

$1.081 \mathrm{E}+000$

$9.287 \mathrm{E}+000$

$2.432 \mathrm{E}-020$

$1.218 \mathrm{E}-030$

3. $250 \mathrm{E}+050$

$4.320 \mathrm{E}+100$

$9.750 \mathrm{E}+030$

$8.264 \mathrm{E}-020$

5.910E-09 0

$1.680 \mathrm{E}+040$

$1.890 \mathrm{E}+020$

$3.220 \mathrm{E}+02 \quad 0$

$1.000 \mathrm{E}+020$

1. $220 \mathrm{E}+040$

$2.020 \mathrm{E}+030$

$4.930 \mathrm{E}+00 \quad 0$

$5.910 \mathrm{E}+030$

$2.960 \mathrm{E}+000$

4. 460 E+03 0

$2.540 \mathrm{E}-010$

$4.460 \mathrm{E}+030$

$2.540 \mathrm{E}-010$

1

$\frac{1}{1}$

$\begin{array}{ll}\text { SCO } & \text { SCO }\end{array}$

SCO SCO

NO

HONO

E

TEMP

HO

$\mathrm{H} 2 \mathrm{O}$

$2.322 \mathrm{E}+00$

4.529E+00 8.810E-09 1.650E-05

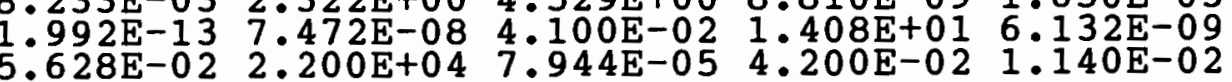

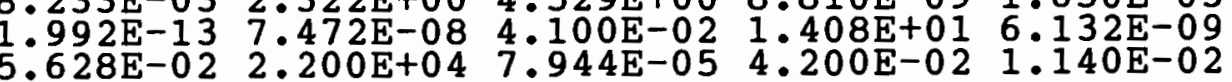


TABLE V

MATHEMATICA SOLUTION FOR THE CLEAN AIR MECHANISM

\section{INPUT:}

$\mathrm{dO} / \mathrm{dt}=\mathrm{R} 1-\mathrm{R} 2-\mathrm{R} 3-\mathrm{R} 4-\mathrm{R} 14+\mathrm{R} 15+\mathrm{R} 18=0$

$\mathrm{dO}_{3} / \mathrm{dt}=\mathrm{R} 2-\mathrm{R} 5+\mathrm{R} 35-\mathrm{R} 16-\mathrm{R} 6-\mathrm{R} 15-\mathrm{R} 25-\mathrm{R} 30=0$

$\mathrm{dNO}_{2} / \mathrm{d} t=\mathrm{R} 5-\mathrm{R} 1+2 \mathrm{R} 8-\mathrm{R} 22+2 \mathrm{R} 7-\mathrm{R} 6-\mathrm{R} 3+\mathrm{R} 26-\mathrm{R} 21+\mathrm{R} 21-\mathrm{R} 4+\mathrm{R} 9+\mathrm{R} 10-$

$\mathrm{R} 27+\mathrm{R} 28+\mathrm{R} 14-\mathrm{R} 12+\mathrm{R} 12+\mathrm{R} 29=0$

$\mathrm{dNO} / \mathrm{dt}=\mathrm{R} 1-\mathrm{R} 5+\mathrm{R} 36+\mathrm{R} 20-\mathrm{R} 19-2 \mathrm{R} 8-\mathrm{R} 7+\mathrm{R} 3-\mathrm{R} 26-\mathrm{R} 12-\mathrm{R} 13=0$

$\mathrm{dNO}_{3} / \mathrm{dt}=\mathrm{R} 6-\mathrm{R} 7+\mathrm{R} 4-\mathrm{R} 9+\mathrm{R} 10+\mathrm{R} 23-\mathrm{R} 14-\mathrm{R} 12-\mathrm{R} 13-\mathrm{R} 34-\mathrm{R} 33=0$

$\mathrm{dN}_{2} \mathrm{O}_{5} / \mathrm{dt}=\mathrm{R} 9-\mathrm{R} 10-\mathrm{R} I 1=0$

$\mathrm{dHNO}_{3} / \mathrm{dt}=\mathrm{R} 22+\mathrm{R} 21-\mathrm{R} 23+2 \mathrm{R} 11+\mathrm{R} 34+\mathrm{R} 33=0$

$\mathrm{dO}^{1} \mathrm{D} / \mathrm{dt}=\mathrm{R} 16-\mathrm{R} 18-\mathrm{R} 17=0$

$\mathrm{dHO} / \mathrm{dt}=\mathrm{R} 20-\mathrm{R} 19-\mathrm{R} 22+2 \mathrm{R} 17-\mathrm{R} 26-\mathrm{R} 24-\mathrm{R} 23-\mathrm{R} 25-\mathrm{R} 29+\mathrm{R} 30=0$

$\mathrm{dHONO} / \mathrm{dt}=\mathrm{R} 21+\mathrm{R} 19-\mathrm{R} 20=0$

$\mathrm{dCO} / \mathrm{dt}=\mathrm{R} 37-\mathrm{R} 24=0$

$\mathrm{dHO}_{2} / \mathrm{dt}=\mathrm{R} 24-\mathrm{R} 26-\mathrm{R} 27+\mathrm{R} 28+\mathrm{R} 25-\mathrm{R} 30-\mathrm{R} 34-\mathrm{R} 33-2 \mathrm{R} 32-2 \mathrm{R} 31=0$

$\mathrm{dHNO}_{4} / \mathrm{dt}=\mathrm{R} 27-\mathrm{R} 28-\mathrm{R} 29=0$

This input was run through Mathematica (Ver \#1.2), and the following solution was obtained for the reaction rates:

SOLUTION :

$R 1=(3 R 11 / 2)+R 12+R 13+(3 R 17 / 2)+(R 21 / 2)-(3 R 23 / 2)-$

$(R 29 / 2)+R 30+R 33+R 34-(R 35 / 2)-(R 36 / 2)-(R 37 / 2)+R 5+R 7+R 8$

$R 3=(-R 11 / 2)-(R 17 / 2)-(R 21 / 2)+(R 23 / 2)-(R 29 / 2)-R 30-R 31-R 32-R 33-$ $R 34+(R 35 / 2)-(R 36 / 2)+(R 37 / 2)+R 8$

$R 9=R 12+R 13-R 21-(R 36 / 2)$

$R 10=-R 11+R 12+R 13-R 21-(R 36 / 2)$

$R 14=-R 11-R 12-R 13+R 23-R 33-R 34+R 4+R 6-R 7$

$R 15=-R 11-R 16-R 17+R 2-R 21+R 23-2 R 30-R 31-R 32-R 33-R 34+R 35+R 37-R 5-$ R6

$\mathrm{R} 18=\mathrm{R} 16-\mathrm{R} 17$

$\mathrm{R} 19=\mathrm{R} 20-\mathrm{R} 21$ 
TABLE V

MATHEMATICA SOLUTION FOR THE CLEAN AIR MECHANISM (continued)

$R 22=-2 R 11-R 21+R 23-R 33-R 34$

$\mathrm{R} 24=\mathrm{R} 37$

$\mathrm{R} 25=\mathrm{R} 11+\mathrm{R} 17+\mathrm{R} 21-\mathrm{R} 23+\mathrm{R} 30+\mathrm{R} 31+\mathrm{R} 32+\mathrm{R} 33+\mathrm{R} 34-\mathrm{R} 37$

$R 26=R 11+R 17+R 21-R 23-R 29-R 31-R 32$

$R 27=R 28+R 29$

The input file was read into Mathematica as a set of simultaneous equations that all were equal to zero. The input file had the following format:

$$
\text { Solve }[\{\text { eqn } 1==0, \text { eqn } 2==0, \ldots, \text { eqn } 13==0\}]
$$

where eqn 1 was the first equation listed in the input section. The file was then retrieved into Mathematica by issuing the following commands from the mathematica prompt:

\section{OpenRead[ "filename"]}

Read[ "filename"]

this would then cause mathematica to execute the command(s) listed in the file, and produce any pertinent output, see the output section. 
TABLE VI

TEN-STEP MECHANISM

/* comments*/

$\$$ command const err $=1 e-3$ tprnt $=3000$ tstep $=3000$ stopp $=1.0 E+05$ reactionout smallerr $=1 e-25$

isop $=.0002$ reactionout

\$reaction

\begin{tabular}{|c|c|c|c|c|c|c|c|c|}
\hline $1 \mathrm{NO}$ & 03 & $=$ & $\mathrm{NO} 2$ & & & $1.50 \mathrm{E}+01$ & 0 . & \\
\hline $2 \mathrm{NO} 2$ & HV & $=$ & No & 03 & HV & $1.60 \mathrm{E}-01$ & 0 . & \\
\hline 303 & $\mathrm{HV}$ & $=$ & HO & HO & HV & $9.40 \mathrm{E}-06$ & 0 . & \\
\hline $4 \mathrm{CO}$ & HO & $=$ & HO2 & & & $4.50 E+02$ & 0 . & \\
\hline $5 \mathrm{HO} 2$ & No & $=$ & NO2 & HO & & $1.20 E+04$ & 0 . & \\
\hline $6 \mathrm{HO}$ & NO2 & $=$ & & & & $1.80 E+04$ & 0 . & \\
\hline $7 \mathrm{SO} 3$ & & $=$ & 03 & $\mathrm{SO} 3$ & & $1.00 \mathrm{E}-00$ & 0 . & \\
\hline $8 \mathrm{SCO}$ & & $=$ & $\mathrm{CO}$ & $\mathrm{sCO}$ & & $1.00 \mathrm{E}-00$ & 0. & \\
\hline 9SNO & & $=$ & NO & SNO & & $1.00 \mathrm{E}-00$ & 0 . & \\
\hline $10 \mathrm{HO}$ & $\mathrm{HO} 2$ & $=$ & $\mathrm{H} 2 \mathrm{O}$ & 02 & & 0 & 0 . & $4.40 e+04$ \\
\hline $11 \mathrm{NO}$ & & $=$ & & & & 0 & 0 . & $1.39 \mathrm{E}-06$ \\
\hline $12 \mathrm{NO} 2$ & & $=$ & & & & 0 & 0 . & $1.39 \mathrm{E}-05$ \\
\hline 1303 & & $=$ & & & & 0 & 0 . & $1.39 \mathrm{E}-05$ \\
\hline $14 \mathrm{CO}$ & & $=$ & & & & 0 & 0 . & $1.39 \mathrm{E}-06$ \\
\hline
\end{tabular}

\$INIT

$03 \mathrm{CO}$ NO SCO HV

$1.000 \mathrm{e}-051.000 \mathrm{e}-11 \quad 5.000 \mathrm{E}-03 \quad 1 \mathrm{E}-081$

\section{\$CONST}

SNO $\mathrm{SO} 3 \mathrm{SCO}$

\$ISOP

$\begin{array}{llll}1 & 1 & 11 & 9\end{array}$

$\mathrm{SO} 3$

SNO

1

1

$1 e-9 \quad 5 e-9 \quad 1 e-8 \quad 5 e-8$ le-7 $5 e-7$

$1 e-6 \quad 5 e-6 \quad 1 e-5$

$1 e-10 \quad 5 e-10 \quad 1 e-9 \quad 5 e-9 \quad 1 e-8$

$5 e-8 \quad 1 e-7 \quad 5 e-7 \quad 1 e-6 \quad 5 e-6 \quad 1 e-5$

send 
TABLE VII

TEN-STEP MECHANISM, CHEMISTRY, AND MATHEMATICA SOLUTIONS

R1 $\mathrm{S}_{\mathrm{NO}}$

R2 $\mathrm{S}_{03}$

R3 $\mathrm{S}_{\mathrm{CO}}$

$\begin{array}{llll}\mathrm{R} 4 & \mathrm{NO}+\mathrm{O}_{3} & --->> \\ \mathrm{R} 5 & \mathrm{NO}_{2}+ & \mathrm{hV} & --->\end{array}$

R6 $\mathrm{O}_{3}+$ hv $\stackrel{\mathrm{H}_{2} \mathrm{O}}{--->}$

$\mathrm{R} 7 \mathrm{HO}+\mathrm{CO}-\mathrm{O}_{2}$

$\mathrm{R} 8 \mathrm{HO}_{2}+$ NO $---->$

R9 $\mathrm{NO}_{2}+\mathrm{HO}---->$

$\mathrm{RIO} \mathrm{HO}_{2}+\mathrm{HO}---->$
NO

$\mathrm{O}_{3}$

$\mathrm{CO}$

$\mathrm{NO}_{2}+\mathrm{O}_{2}$

NO $+\mathrm{O}_{3}$

$2 \mathrm{HO}+\mathrm{O}_{2}$

$\mathrm{HO}_{2}+\mathrm{CO}_{2}$

$\mathrm{NO}_{2}+\mathrm{HO}$

$\mathrm{HNO}_{3}$

$\mathrm{H}_{2} \mathrm{O}+\mathrm{O}_{2}$

This mechanism provides six reactions, with six species; HO, $\mathrm{NO}, \mathrm{NO}_{2}, \mathrm{CO}, \mathrm{HO}_{2}$, and $\mathrm{O}_{3}$.

The solution to the ten step mechanism, by using the steady state approximation is:

$$
\begin{aligned}
& R 9=S_{\mathrm{NO}} \\
& R 7=\mathrm{S}_{\mathrm{CO}} \\
& \mathrm{R} 6 \mathrm{~S}
\end{aligned}
$$

This provides a solution to the mechanism for the reactions noted above in terms of the independent variables, the source rates.

For the ten step reaction to have a positive value for the rates listed above the following inequalities have to hold.

$$
\begin{aligned}
R 6: & 2 S_{C O}+2 S_{03} \geq S_{N O} \\
R 8: & 2 S_{C O}+3 S_{N O} \geq 2 S_{03} \\
R 10: & 2 S_{C O}+2 S_{03} \geq 3 S_{N O}
\end{aligned}
$$


TABLE VIII

SOLUTIONS TO ELEMENTARY MECHANISMS AND CLEAN AIR MECHANISM TEN STEP MECHANISM:

$$
\begin{aligned}
\mathrm{R} 6 & =\left(2 \mathrm{~S}_{\mathrm{CO}}+2 \mathrm{~S}_{\mathrm{O} 3}-\mathrm{S}_{\mathrm{NO}}\right) / 4 \\
\mathrm{R} 8 & =\left(2 \mathrm{~S}_{\mathrm{CO}}-2 \mathrm{~S}_{03}+3 \mathrm{~S}_{\mathrm{NN}}\right) / 4 \\
\mathrm{R} 10 & =\left(2 \mathrm{~S}_{\mathrm{CO}}+2 \mathrm{~S}_{03}-3 \mathrm{~S}_{\mathrm{NO}}\right) / 4
\end{aligned}
$$

ELEVEN STEP MECHANISM:

$$
\begin{gathered}
\mathrm{R} 6=\left(2 \mathrm{~S}_{\mathrm{CO}}+2 \mathrm{~S}_{03}-\mathrm{S}_{\mathrm{NO}}\right) / 4 \\
\mathrm{R} 8-\mathrm{R} 11=\left(2 \mathrm{~S}_{\mathrm{CO}}-2 \mathrm{~S}_{03}+3 \mathrm{~S}_{\mathrm{NO}}\right) / 4 \\
\mathrm{R} 10=\left(2 \mathrm{~S}_{\mathrm{CO}}+2 \mathrm{~S}_{03}-3 \mathrm{~S}_{\mathrm{NO}}\right) / 4
\end{gathered}
$$

TWELVE STEP MECHANISM:

$$
\begin{aligned}
& R 6+R 12=\left(2 S_{C O}+2 S_{03}-S_{N O}\right) / 4 \\
& R 8-R 11=\left(2 S_{C O}-2 S_{03}+3 S_{N O}\right) / 4 \\
& R 6-R 10=\left(2 S_{C O}+2 S_{03}-3 S_{N O}\right) / 4
\end{aligned}
$$

THIRTEEN STEP MECHANISM:

$$
4 \mathrm{R} 6+4 \mathrm{R} 12+\mathrm{R} 13=2 \mathrm{~S}_{\mathrm{CO}}+2 \mathrm{~S}_{03}-\mathrm{S}_{\mathrm{NO}}
$$

FOURTEEN STEP MECHANISM:

$$
\begin{aligned}
& 4 R 6+2 R 12+2 R 13+R 14-R 11=2 S_{C O}+2 S_{03}-S_{N O} \\
& 4 R 10+2 R 12+2 R 13-3 R 11-R 14=2 S_{C O}+2 S_{03}-3 S_{N O} \\
& 4 R 8+3 R 11+2 R 12+R 14-2 R 13=2 S_{C O}-2 S_{03}+3 S_{N O}
\end{aligned}
$$

LARGE CLEAN AIR MECHANISM:

$2\{R 5+R 6+R 13+R 15+R 16+R 17+R 23+2 R 30+R 31+R 32+R 33+R 34-R 2-R 10-R 12\}$

$$
=2 \mathrm{~S}_{\mathrm{CO}}+2 \mathrm{~S}_{03}-\mathrm{S}_{\mathrm{NO}}
$$

$2\{R 15+R 16+R 17-R 2-R 23+2 R 30+R 31+R 32+R 33+R 34+R 5+R 6-3 R 12-2 R 11-$ $3 R 10+3 R 13-2 R 21\}=2 S_{C O}+2 S_{03}-3 S_{\mathrm{NO}}$

$2\{R 17-R 23+R 30+R 31+R 32+R 33+R 34-2 R 25-R 15-R 16+R 2-R 5-R 6+3 R 12-$

$$
2 R 11-3 R 10+3 R 13-2 R 21\}=2 S_{C O}-2 S_{03}+3 S_{\text {NO }}
$$


TABLE IX

ELEVEN THROUGH FOURTEEN STEP MECHANISMS

Reactions common to the Eleven and Thirteen step Mechanisms:

R1 $S_{\text {NO }} \quad \cdots$ NO

R2 $\mathrm{S}_{03} \quad-\cdots-\mathrm{O}_{3}$

R3 $\mathrm{S}_{\mathrm{CO}}$

$\mathrm{R} 4 \mathrm{NO}+\mathrm{O}_{3} \ldots-\cdots \mathrm{NO}_{2}+\mathrm{O}_{2}$

$\mathrm{R} 5 \mathrm{NO}_{2}+\mathrm{h} v+-->\mathrm{NO}+\mathrm{O}_{3}$

$\mathrm{R6} \mathrm{O}_{3}+\mathrm{h} v \quad--->\quad 2 \mathrm{HO}$

$\mathrm{R} 7 \mathrm{HO}+\mathrm{CO}----\mathrm{HO}_{2}+\mathrm{CO}_{2}$

$\mathrm{R} 8 \mathrm{HO}_{2}+\mathrm{NO}-\cdots \mathrm{NO}_{2}+\mathrm{HO}$

$\mathrm{R} 9 \mathrm{NO}_{2}+\mathrm{HO}-\cdots \rightarrow \mathrm{HNO}_{3}$

$\mathrm{R} 10 \mathrm{HO}_{2}+\mathrm{HO}-\cdots-\mathrm{H}_{2} \mathrm{O}+\mathrm{O}_{2}$

$\mathrm{R} 11 \mathrm{HO}+\mathrm{O}_{3}-\cdots-\mathrm{HO}_{2}+\mathrm{O}_{2}$

By adding the following reaction to the above listed eleven, the Twelve step Mechanism is formed:

$\mathrm{R} 12 \mathrm{HO}_{2}+\mathrm{O}_{3}--->\quad \mathrm{HO}+2 \mathrm{O}_{2}$

By adding the following reaction to $\mathrm{R} 1$ through $\mathrm{R} 12$, the Thirteen step Mechanism is formed:

$\mathrm{R} 13 \mathrm{HO}_{2}+\mathrm{HO}_{2}-\cdots \rightarrow \mathrm{H}_{2} \mathrm{O}_{2}+\mathrm{O}_{2}$

By using $R 1$ through $R 10$, and replacing reactions $R 11$ through R13 with the following, the Fourteen step Mechanism is formed:

R11 NO

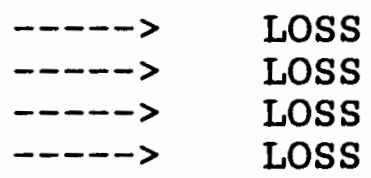

$\mathrm{R} 12 \mathrm{CO}$

$\mathrm{R} 13 \quad \mathrm{O} 3$

R14 NO2

LOSS 


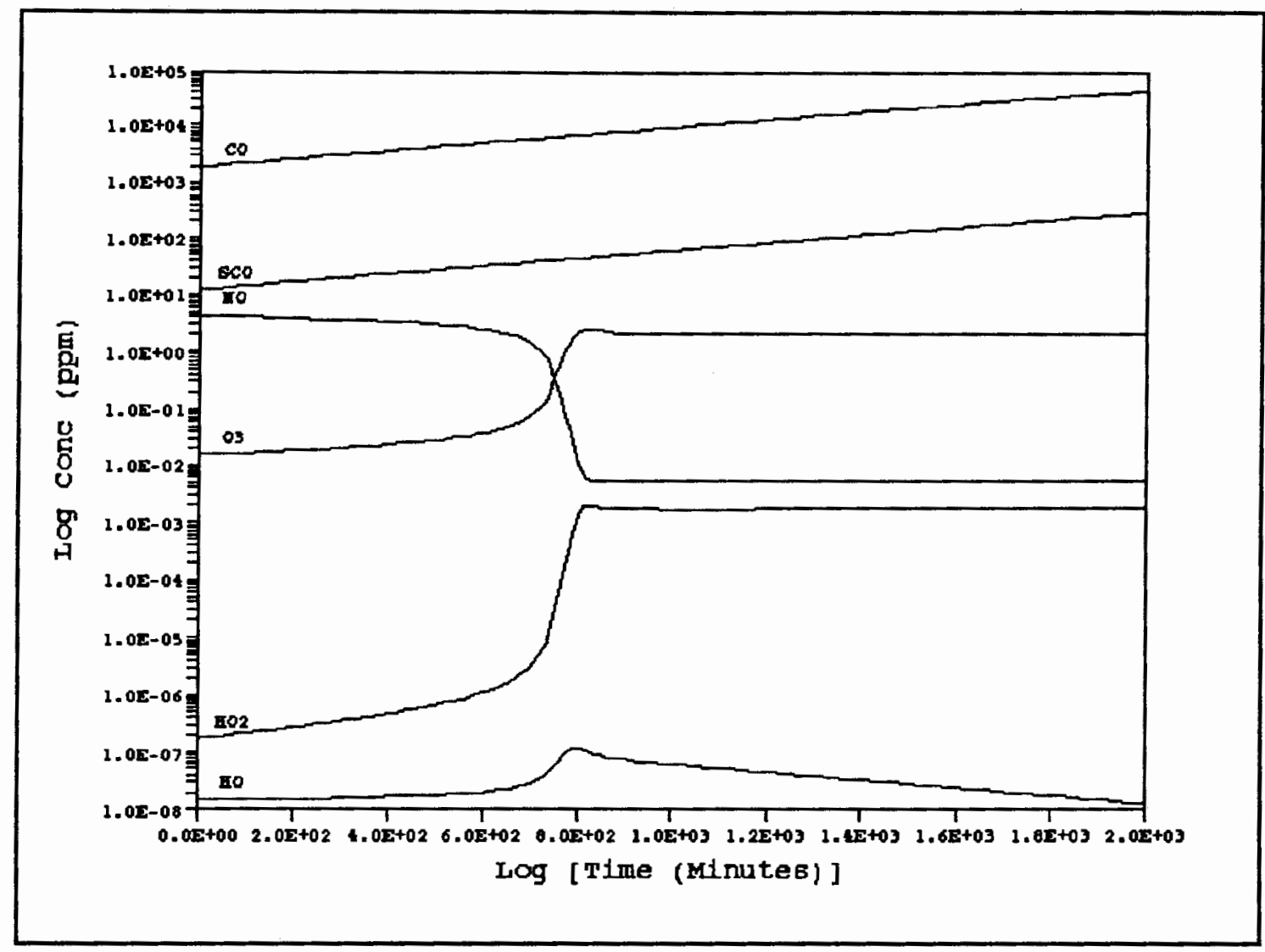

Figure 2. Concentration versus time for reaction species. This figure illustrates the inflection points in the concentrations of the reactants. The inflection point occurs at different places for the forward, and reverse reactions. The inflection occurs at the point corresponding to the first point on the steady-state equilibrium curve that has more than one equilibrium concentration for the species in question, for the given source rate. The equilibrium curve would continue through an "s" shaped path, but kinetics do not allow this. At the last point where there is more than one possible concentration, the system will jump from its current path to the higher or lower leg of the curve. The figure above shows this jump from the path it was following to the other leg, that is the reason for inflection in the center of the figure. 


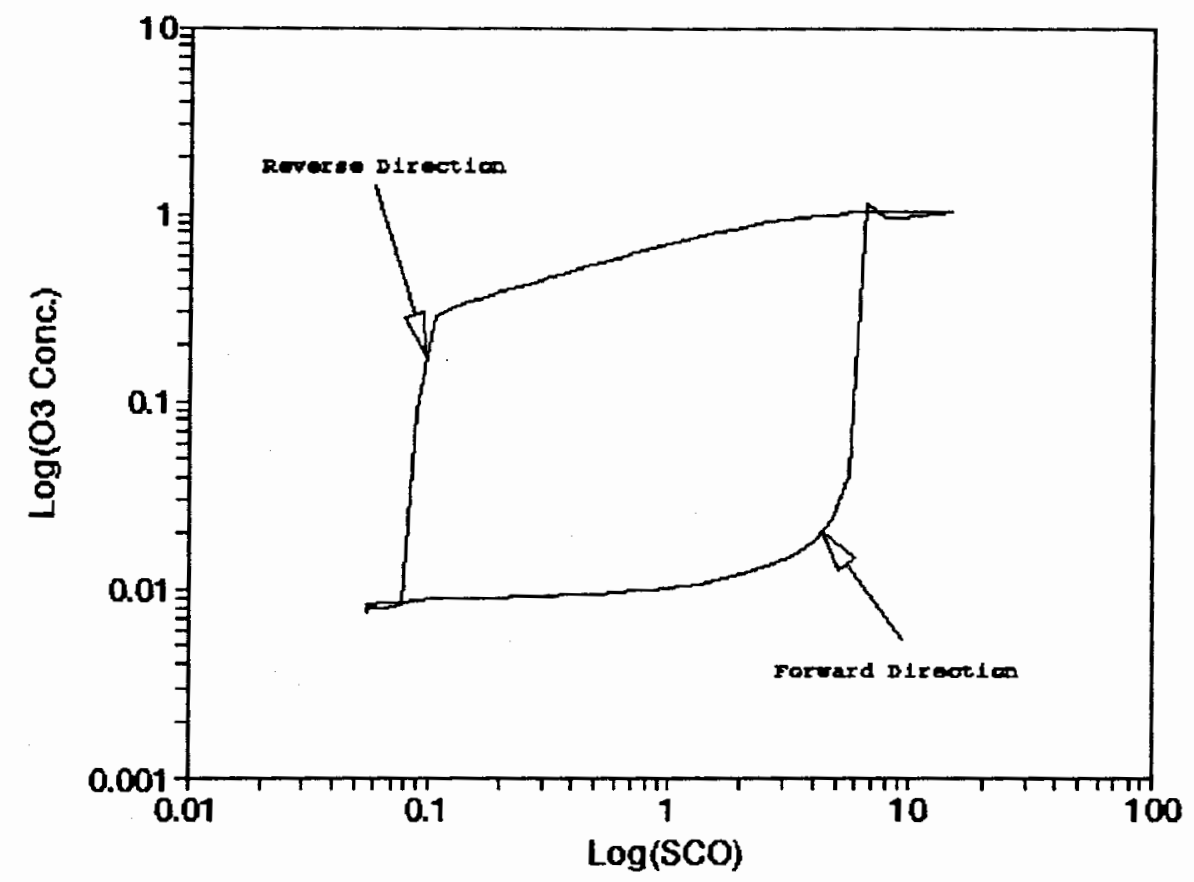

Figure 3. Ozone hysteresis loop. This figure shows the result of running the reaction mechanism with increasing and decreasing source rates. As seen in figure 2 there is an inflection point at the last point where multiple steady-state concentrations can occur. This shows the reaction following the curve in the forward direction, and the concentration begins to climb, but the steadystate solution to the system dictates that it follow an "s" shaped path. At the first bend in the "s" the concentration, since it is run by the kinetics, will jump to the top of the curve, effectively bypassing the switch-back. For the reverse reaction it follows the upper part of the curve, with the concentration dropping, until it hits the upper bend in the curve. At this point it drops to the bottom of the curve, and continues on to lower concentrations. Since the curve is "s" shaped the forward and reverse reactions would be expected to have their respective drops in concentration at different places. 

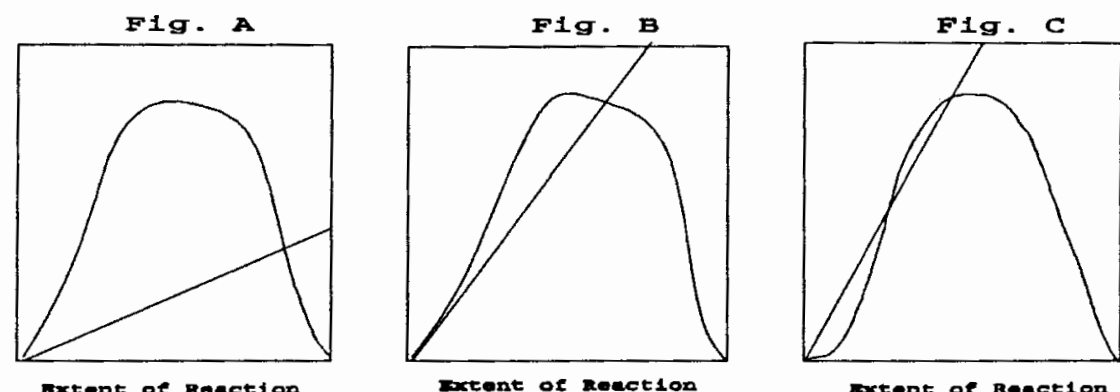

patent of Reection
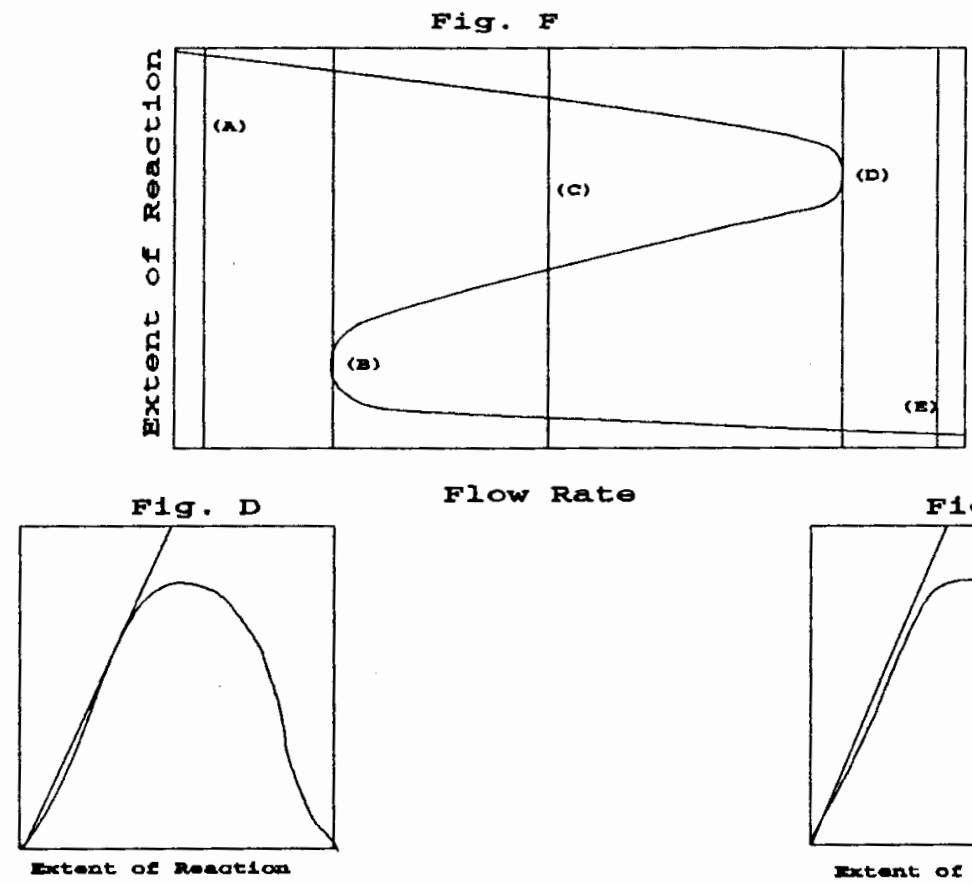

Flow Rate

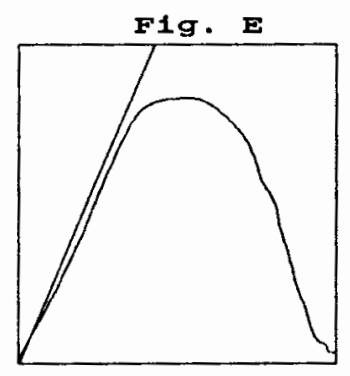

Ixtent of Reraction

Figure 4. Relationship of hysteresis loop and inflection points. This figure illustrates the regions of multistability for a cubic autocatalytic reaction. The center diagram, Fig. F shows the relationship of the solution of the equations for the cubic continuously stirred reactor. The points of intersection and tangency represent solutions where $L 1=L 2$. The vertical lines on Fig $F$ show how they relate to the flow rate, and the extent of the reaction in question. The lines represented by Fig $B$ and $F i g ~ D$ delineate the boundaries of the hysteresis region. 


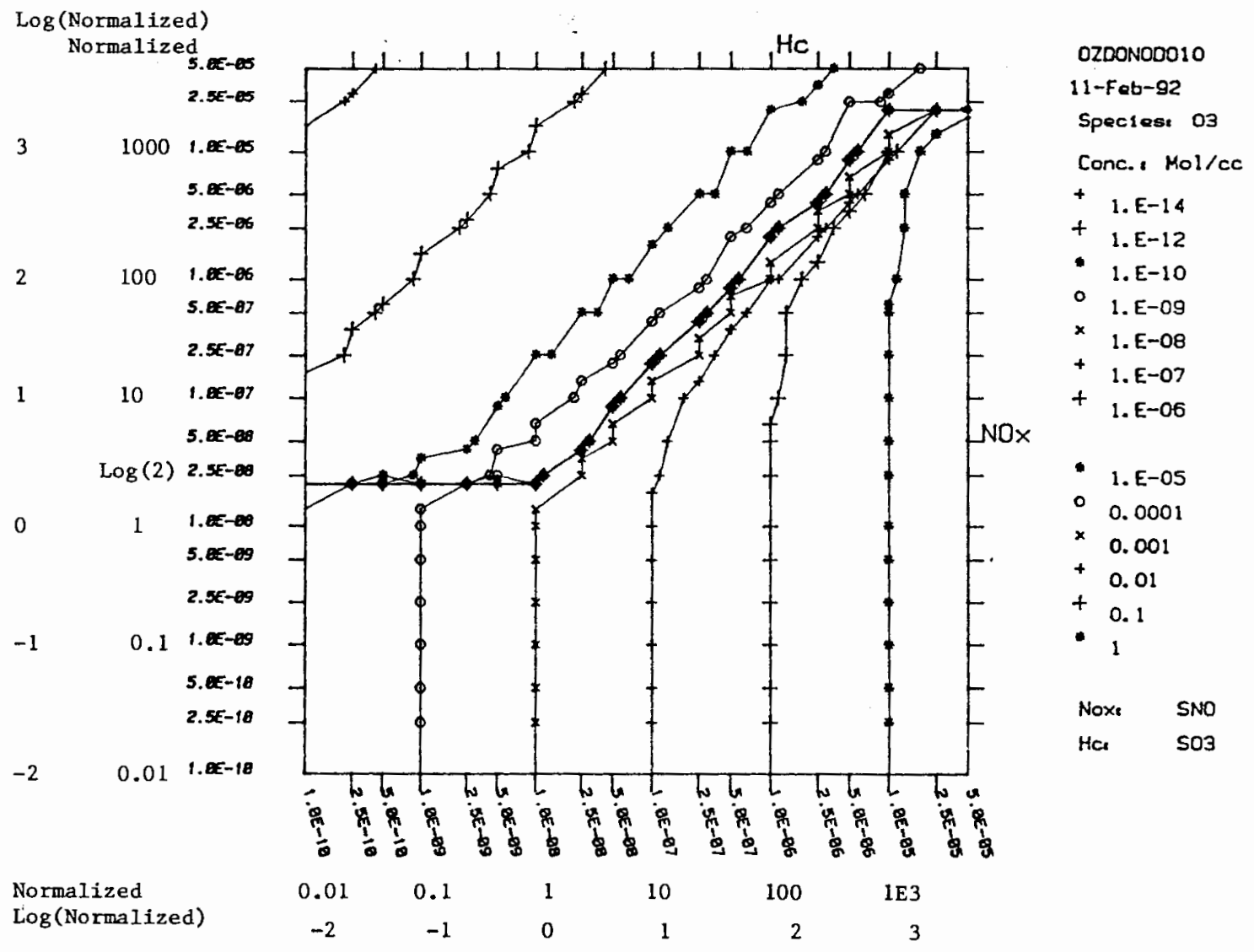

Figure 5. Isopleth for the ten-step mechanism. 


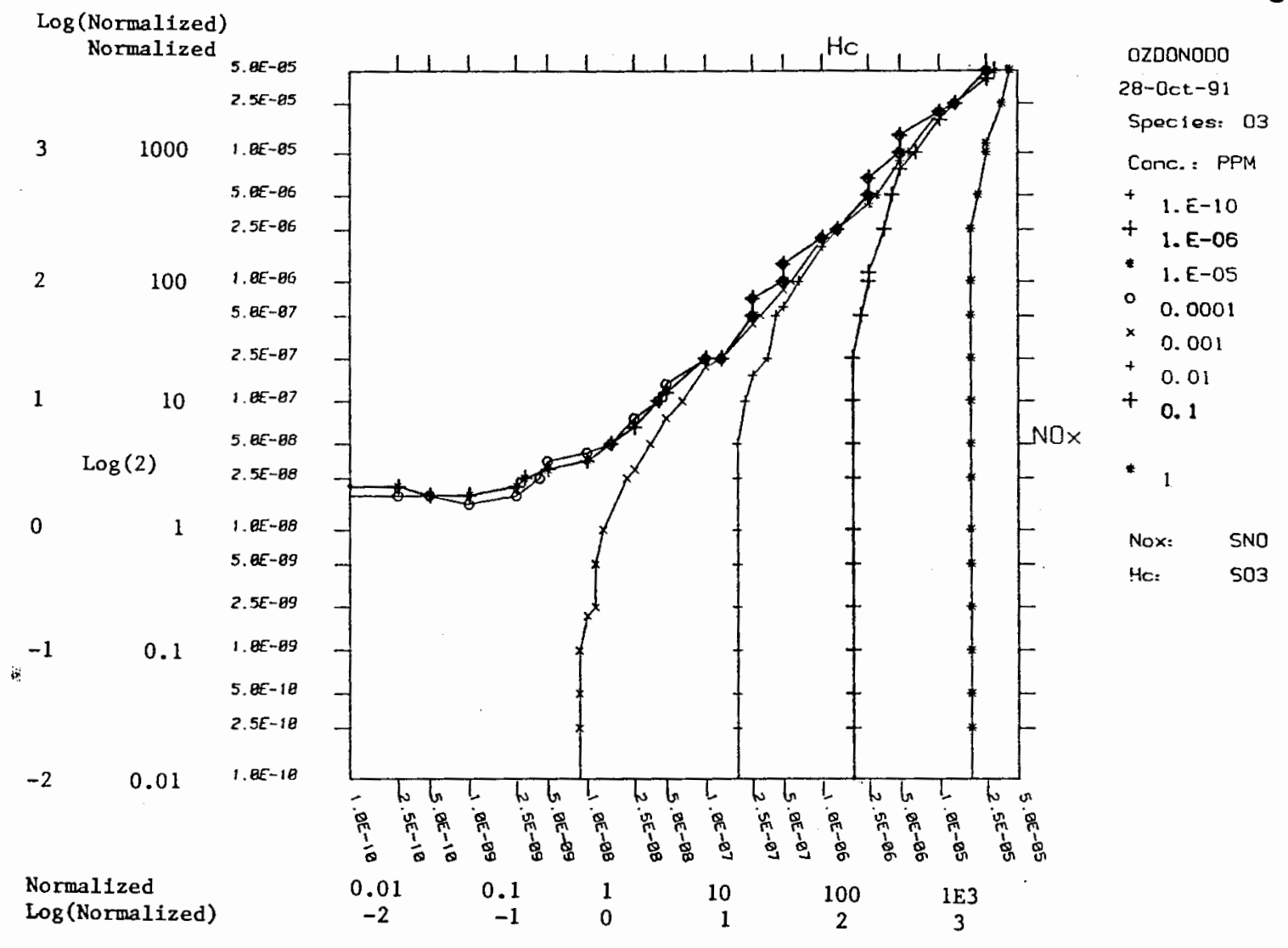

Figure 6. Theoretical isopleth for the ten-step 


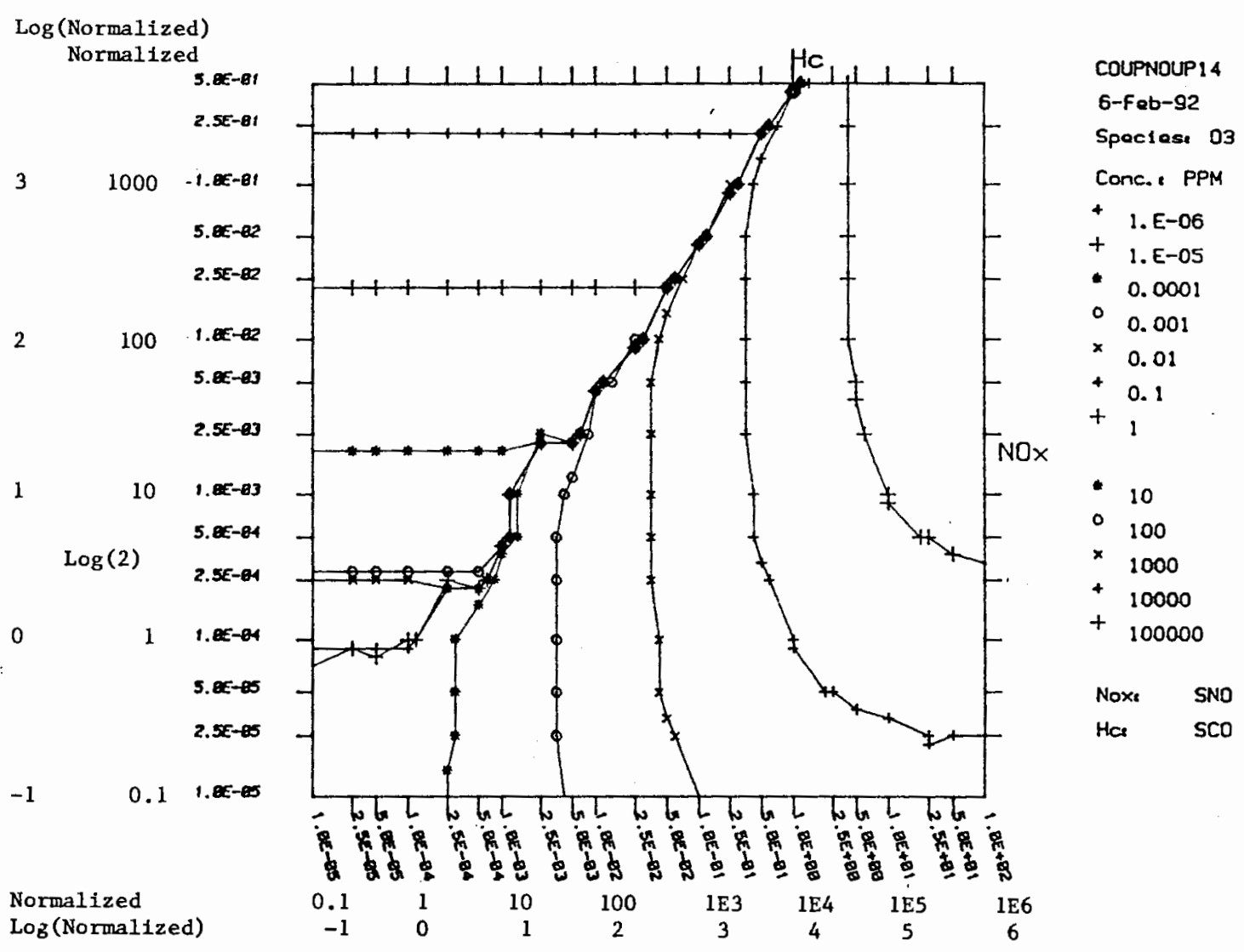

Normaltzed 


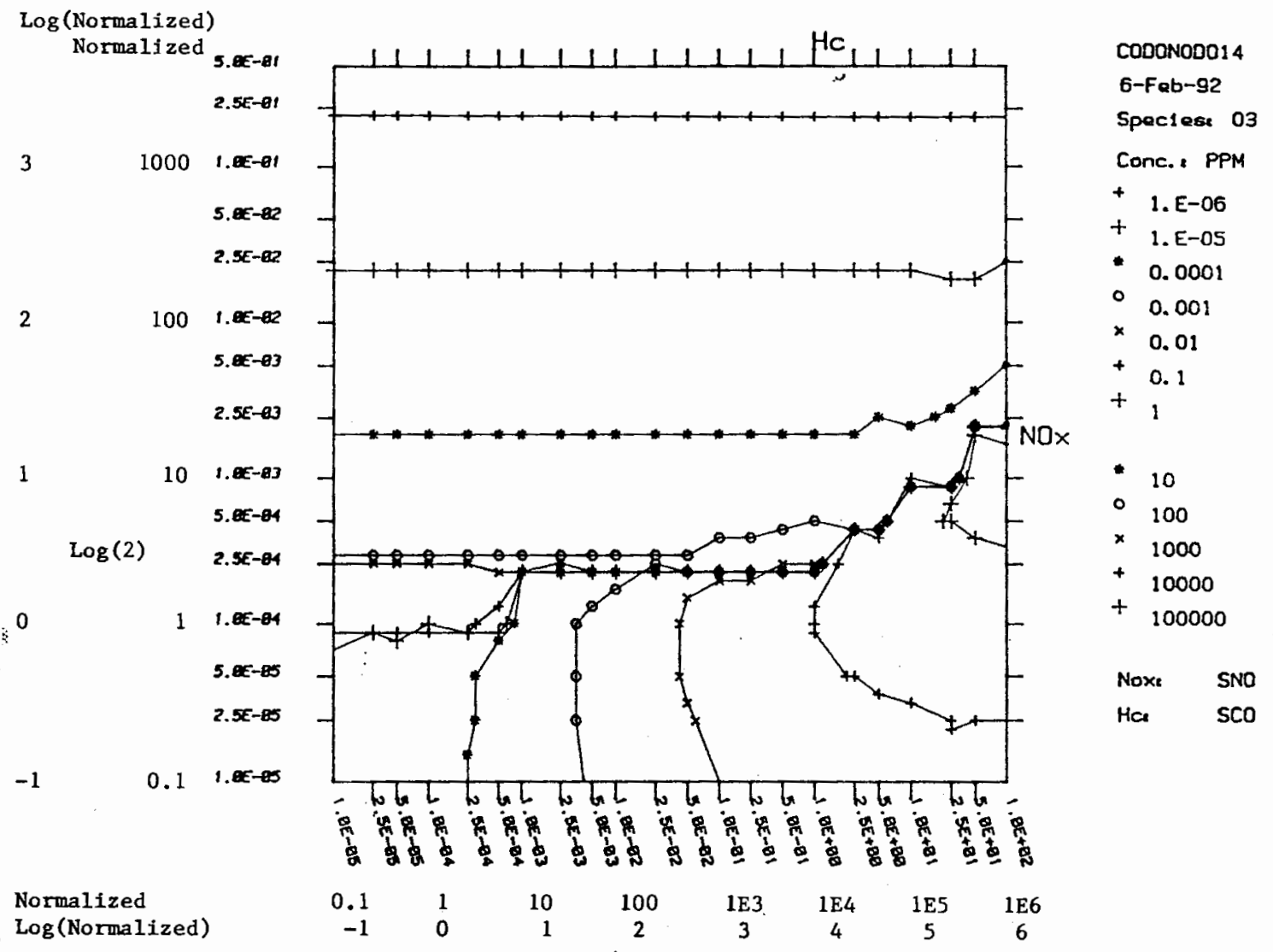

Figure 8. Isopleth for the fourteen step mechanism reverse. Source rates are initially high and progress to low values. 


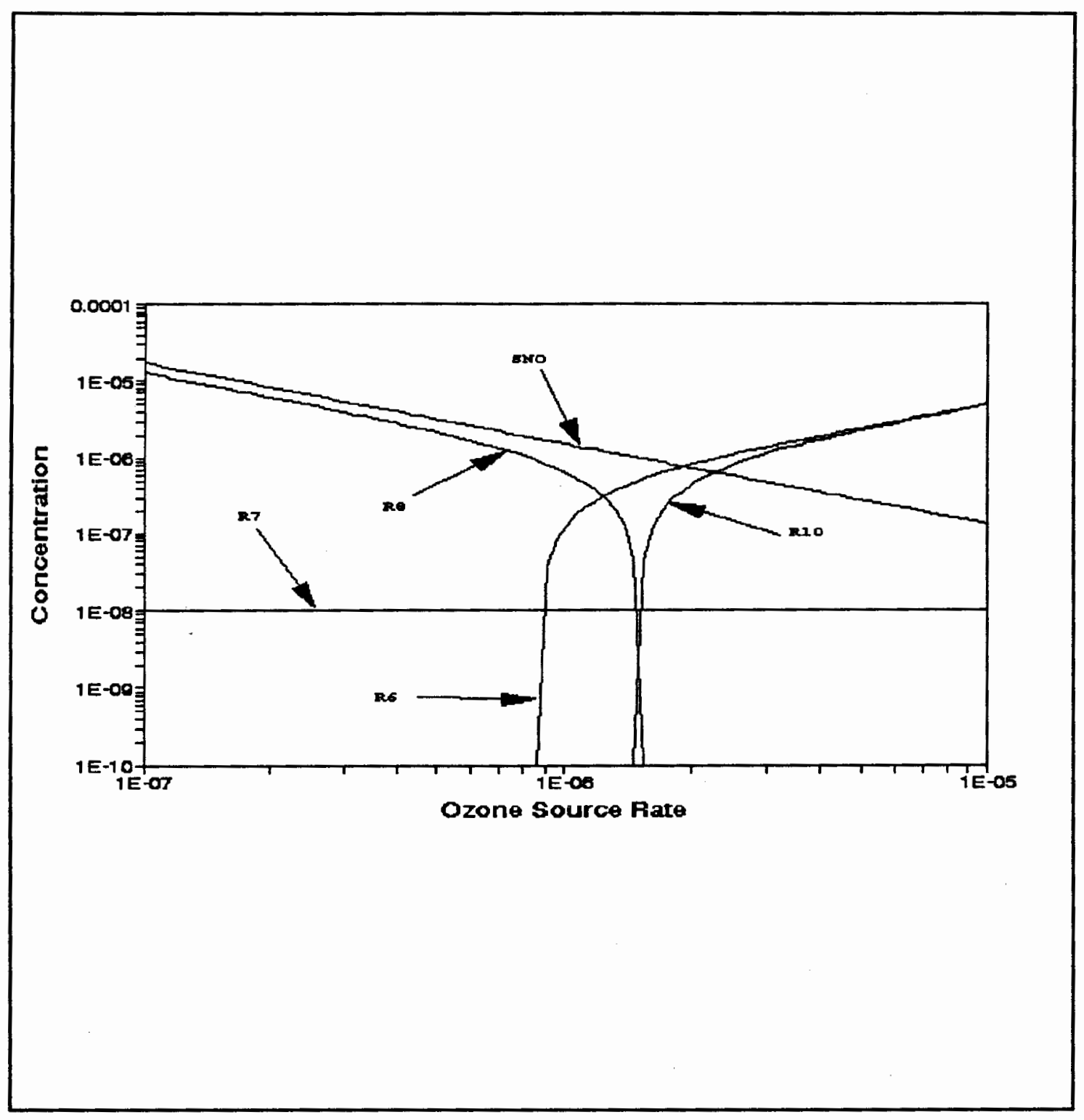

Figure 9. TRSlover plot of the ten step solution. This figure shows a cross section from the isopleth diagrams. It was generated by TRSolver Plus. Lists of the ozone and nitric oxide source rates were supplied while the source rate for CO was held constant, and the program calculated the data for all the other variables. 


\section{CHAPTER IV \\ EXPERIMENTAL STUDY OF HYSTERESIS}

\section{EXPERIMENTAL SETUP}

The experimental part of the hysteresis research was undertaken to determine the feasibility of this phenomena, hysteresis. The experimental setup, shown in Figure 10, was designed and constructed by myself. The Teflon film bag was tested for its ability to transmit Ultra-Violet (UV) radiation, see Figure 11 . The UV wavelengths that the proposed mechanism relied on are $254 \mathrm{~nm}$ (ozone photolysis to produce $O\left(a^{1} D\right)$, and $310-400 \mathrm{~nm}\left(\mathrm{NO}_{2}\right.$ photolysis to produce NO and $O\left(X^{3} P\right)$ ) (Levy 1972)(Cox 1978)(Barton \& Robertson 1975). The bag was then sealed onto a platform which held the inlet and sampling tubes, and a stirring motor. Ozone was allowed to flow into the bag for about one week prior to the beginning of any experiments, this was to allow the destruction of any remaining contaminants on the teflon film (Grosjean \& McMurry 1985). The initial test of the system, to determine if further modification was necessary, was as noted below (Salem 1976);

A. Admit ozone flow, and allow to equilibrate. 
B. Titrate the ozone concentration to approximately $10 \%$ of its initial concentration by the following reaction:

$$
\mathrm{O}_{3}+\mathrm{NO}---\mathrm{NO}_{2}+\mathrm{O}_{2}
$$

C. Turn on soft UV (wavelength=310nm) and from the reaction:

$\mathrm{NO}_{2}+\mathrm{h} v+\mathrm{O}_{2}--->\mathrm{NO}+\mathrm{O}_{3}$

the ozone concentration should increase.

D. Turn on the hard UV (wavelength $=254 \mathrm{~nm}$ ) and from the reaction:

$\mathrm{CO}+\mathrm{NO}+\mathrm{HO}---\mathrm{CO}_{2}+\mathrm{NO}_{2}+\mathrm{O}_{3}$

the ozone concentration should increase

further.

From this series of experiments the reaction container was deemed potentially able to run the proposed mechanism, and obtain useful results. The above listed test scheme did appear to work (Farrow, et. al. 1976). Figure 12 shows the ozone concentration at each step of the above listed experiment.

The reaction was initially done using an ozone generator that produced about $40 \mathrm{ppm}$ of ozone, a $5 \% \mathrm{NO} / \mathrm{N}_{2}$ mixture, and $99.58 \mathrm{CO}$. These were admitted into the bag via flow meters that were controlled by a TRS80 Mod4 non-gate array microcomputer. The flow meters would be set to some initial flow by the operator, then the computer would record 
the data from the ozone monitor, as well as step the flows. This was designed to run unattended for many days to allow sufficient time to allow the bag to equilibrate between each step of the gas flows. Eight-hour steps were found to be appropriate. Results obtained with the above listed setup, and subsequent modeling of the system, provided enough information to determine that this was not an optimum place to run the reaction, which would have needed about two atmospheres of $\mathrm{CO}$ in the reaction vessel to produce the hysteresis effect. So back to the drawing board.

The next significant attempt to run the reaction was done by using the setup noted in Figure 10. This initially did not look like it was going to produce any useful insight into the reaction. Problems arose when the inside of the reaction chamber began to fill with a rust-brown colored dust. A very basic analysis of the dust was done, and a determination was made that it was probably $\mathrm{Fe}(\mathrm{CO})_{5}$ that had been photolyzed to $\mathrm{Fe}_{2}(\mathrm{CO})_{9}$. The contamination ruined three reaction chambers, and resulted in many attempts to try to trap the carbonyl in the Co stream. The Co tank was finally replaced, and the problem went away. The reaction was then run with an ozone source of $0.881 \mathrm{ppm}$, a $58 \mathrm{NO} / \mathrm{N}_{2}$ mixture, and $99.5 \% \mathrm{CO}$. This combination again did not work due to the overwhelming effect on the ozone of the NO and CO (Levine 1985). So the final setup had all the same except 
now a $1 \% \mathrm{CO} / \mathrm{N}_{2}$ was used for the Co source. To determine the initial flows of the reactant gasses the isopleth diagrams for the expanded mechanism were used. The isopleth diagrams were generated using the parameters in the experimental setup. The factors supplied to the computer input file were the dilution rate for the reaction vessel and a range of source rates that could be supplied using the materials on hand. Using a constant No source of $3 \times 10^{-2} \mathrm{ppm} \mathrm{min}^{-1}$, and stepping the Co source from 0 to $3 \mathrm{ppm} \mathrm{min}^{-1}$, the boundaries of the hysteresis region would be delineated. (Since water is a key reactant, and since both ozone and No have the potential to react in an aqueous bubbler, the $\mathrm{CO}$ flow was passed through a water bubbler, resulting in a water concentration proportional to the Co concentration. However, subsequent experiments where No was varied at constant water and other inflow conditions also reproduced the hysteresis.) Figures 16 and 17 show the larger mechanism's isopleth diagrams for the forward and reverse runs. The isopleth in the forward direction starts with low initial concentrations for the reactants, and increases the sources. The isopleth in the reverse direction starts with high initial reactant concentrations, and decreases the sources. The results from this combination are noted in Figures 13, 14, 15 (13 shows the increase in ozone, and its subsequent drop to low concentration, 14 rearranges these 
data into a loop, 15 shows the last two runs). Figure 13 shows the ozone concentration versus time, this is the result of allowing the ozone to equilibrate, then admitting a No and Co flow and then letting the computer take over the stepping of the co every eight hours by increasing the flow by $20 \mathrm{cc} / \mathrm{min} / 8$ hours. This stepping was done till maximum flow is reached, the computer then decreases the flow in a similar manner till zero flow is achieved. This process of increasing/decreasing can be repeated endlessly, in Figure 15 the result of allowing the system to operate for about a week shows the twin peaks of the hysteresis region.

\section{EQUIPMENT}

The equipment utilized in this experiment is shown in Figure 10. The central controller for the whole system is a TRS80-Model 4 microcomputer. Analog to Digital and Digital to Analog converters in the computer's I/O Bus controlled the experimental variables and read the ozone concentration. The control program, see appendix $A$, would take the desired initial input voltage, provided by the operator, and relay this to the TYLAN flow meters. The actual flows through the flow meters were monitored by the computer, and adjusted as needed to maintain the desired flow. The computer also did incremental stepping of the flows to simulate changing emission rates. The monitoring of the reactions progress 
was accomplished by taking the analog output from the DASIBI Ozone monitor, running it through the $A / D$ converter, then recording the value in an output file that would later be plotted to observe the changes in the ozone concentration, see Figure 12. The source of ultraviolet light for the reaction was provided by banks of uv black-lights (F40-BLB), and the hard UV was generated from three germicidal fluorescent lights, sylvania model G30T8 $30 \mathrm{~W}$ lights. 
Hysteresis Research

Experimental setup

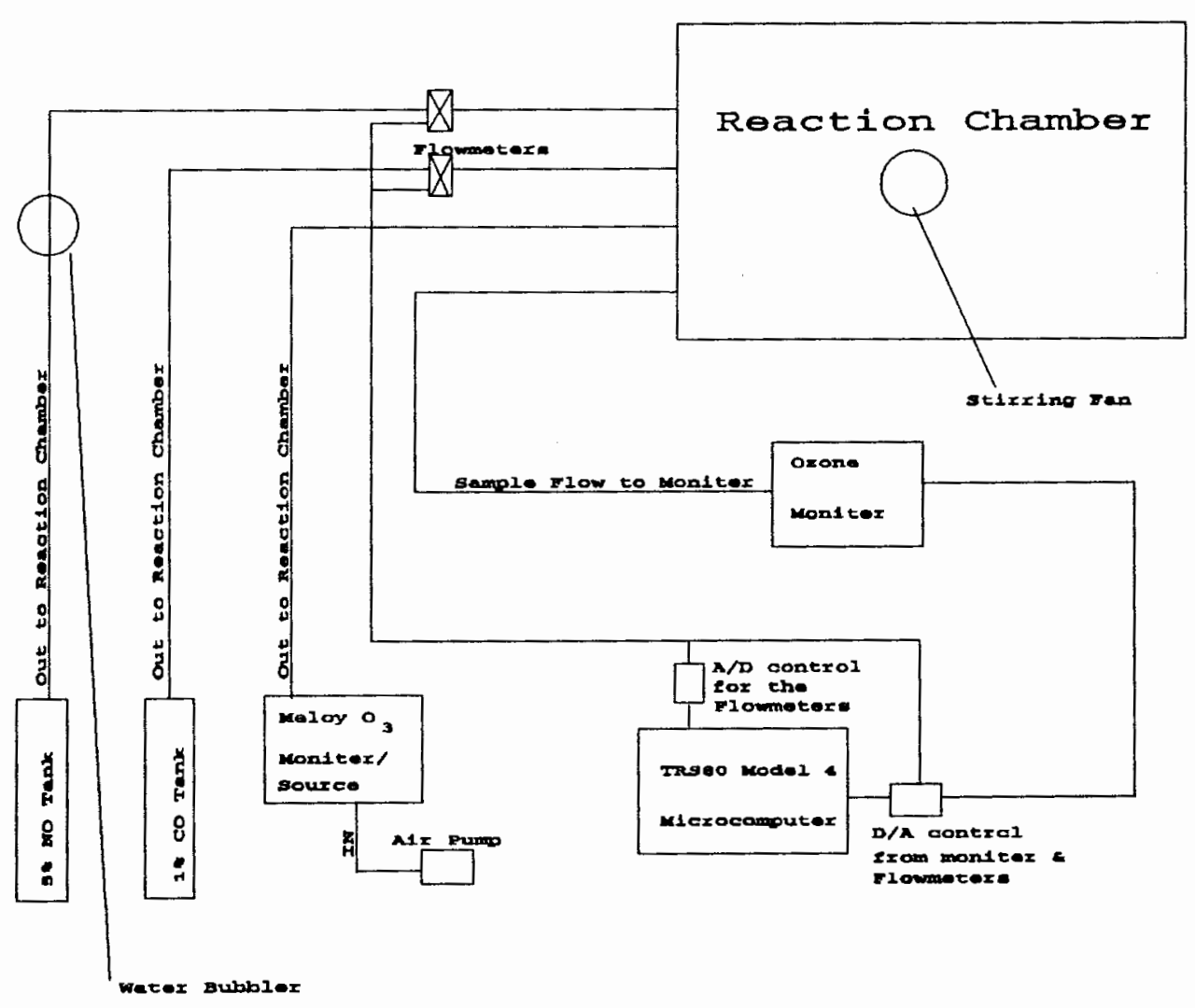

Figure 10. Experimental setup. 


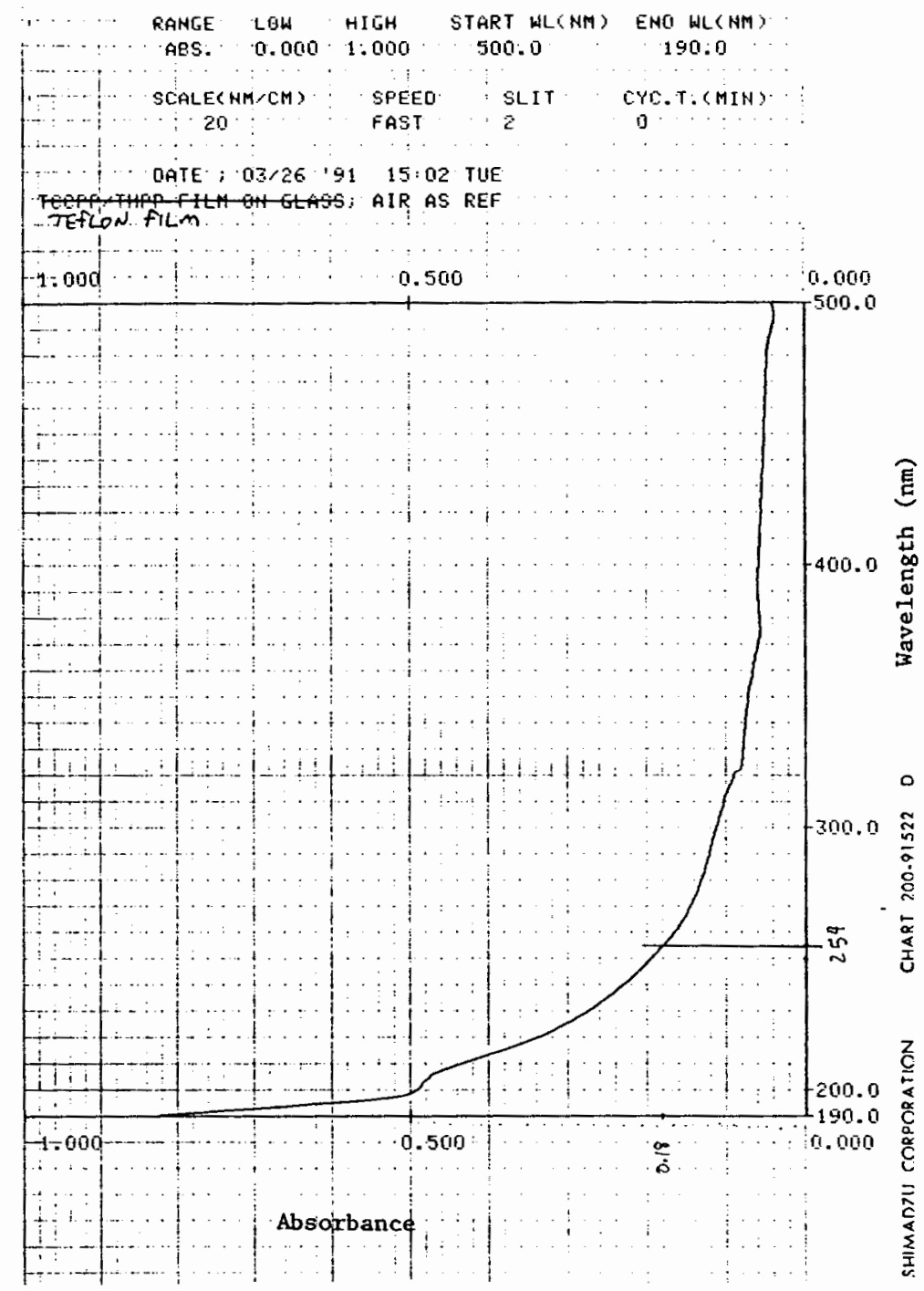

Figure 11. Ultraviolet absorbance spectra for tefion film. This figure shows the absorbance spectra of the film the smog chamber was constructed from. 


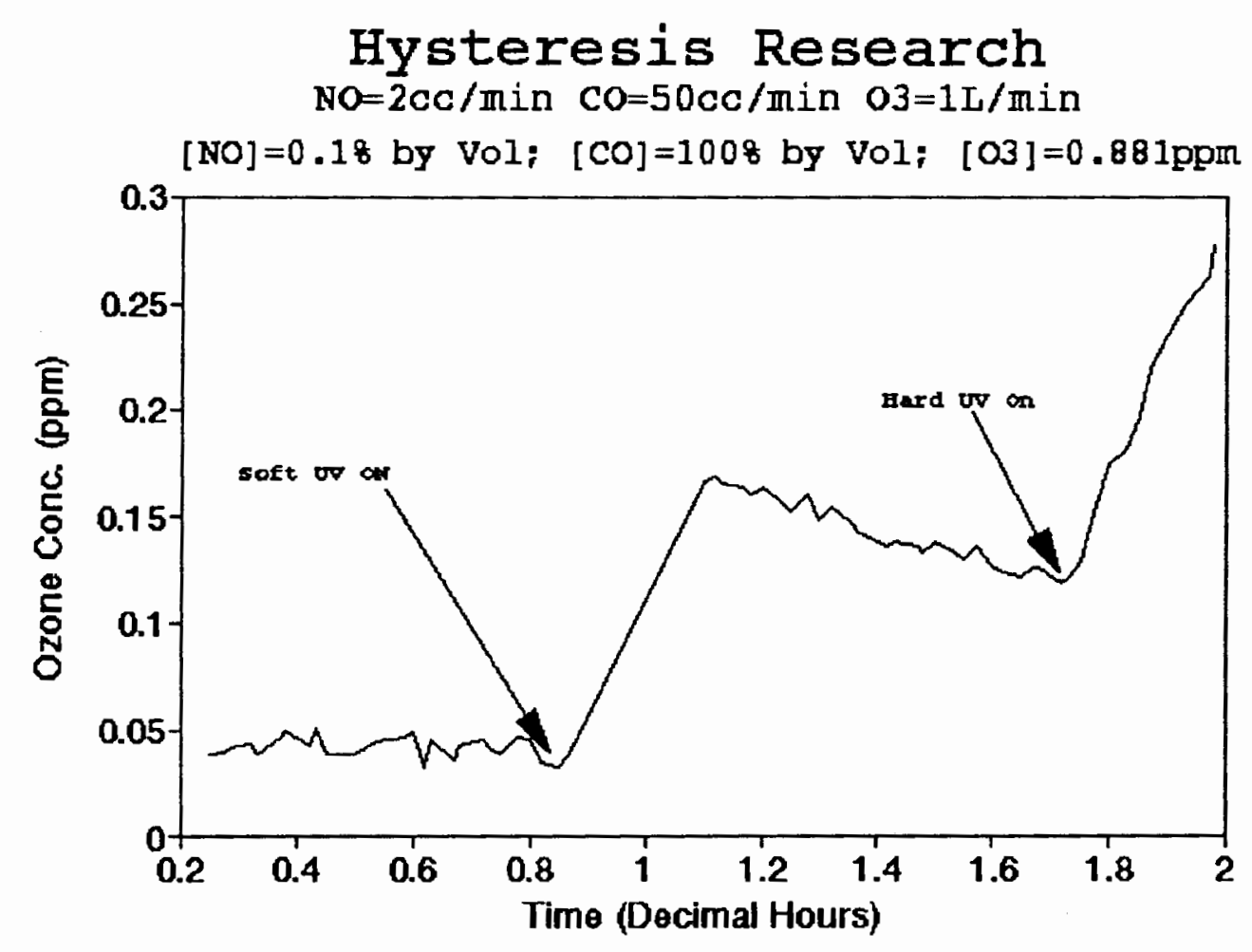

Figure 12, Ozone versus time from the initial bag test. This figure shows the ozone concentration for the initial testing of the experimental system. The source flows are listed above the figure, with the concentrations of the various species. 


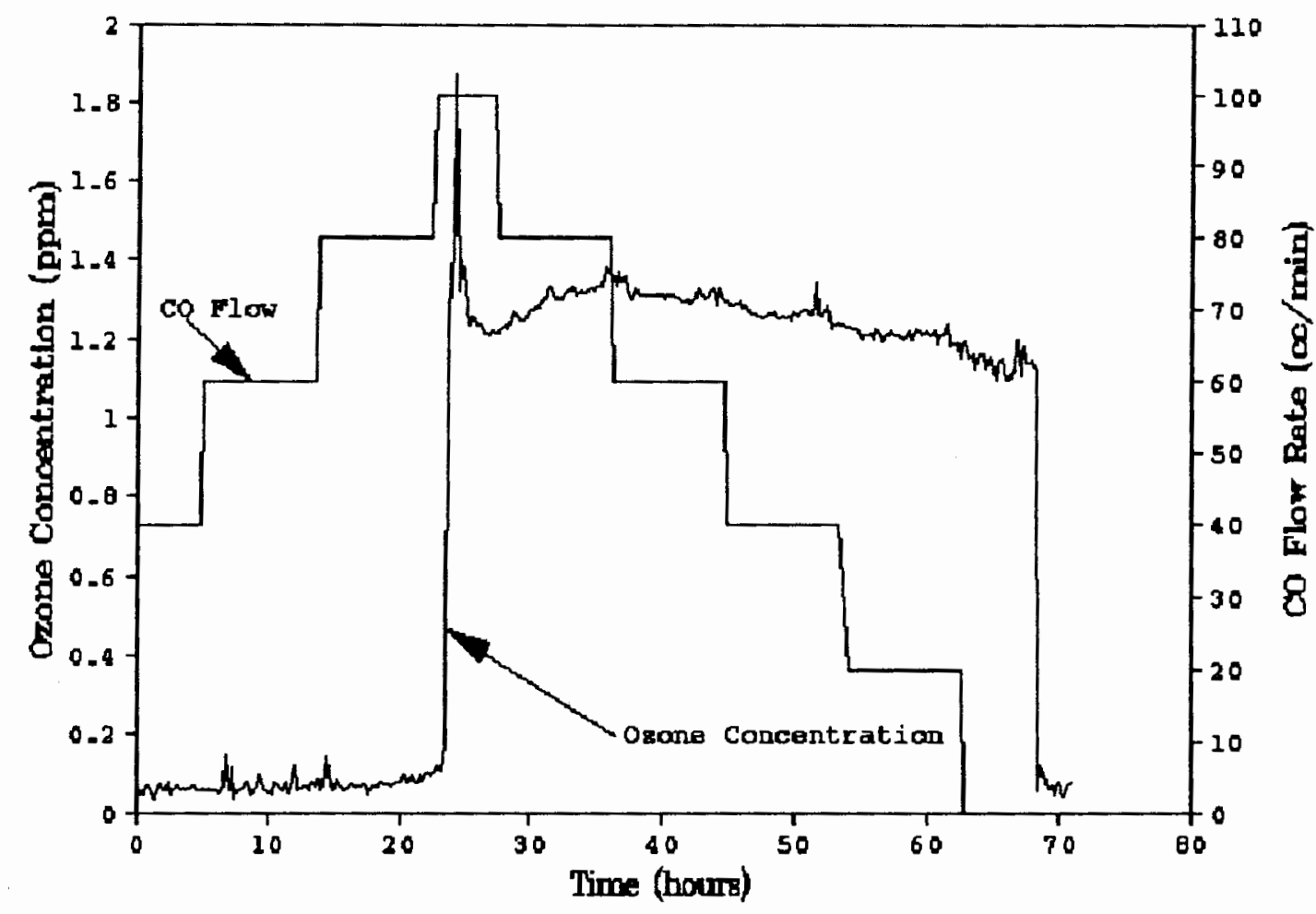

Figure 13. Ozone and Co flow versus time. This figure shows the ozone concentration as it varies with the CO Flow. The inflection points in the Ozone concentration are at notably different $\mathrm{CO}$ Flow rates. The ozone concentration rises to a high value only at high co Flows, and conversely the ozone concentration drops to low values at very low Co Flow rates. 


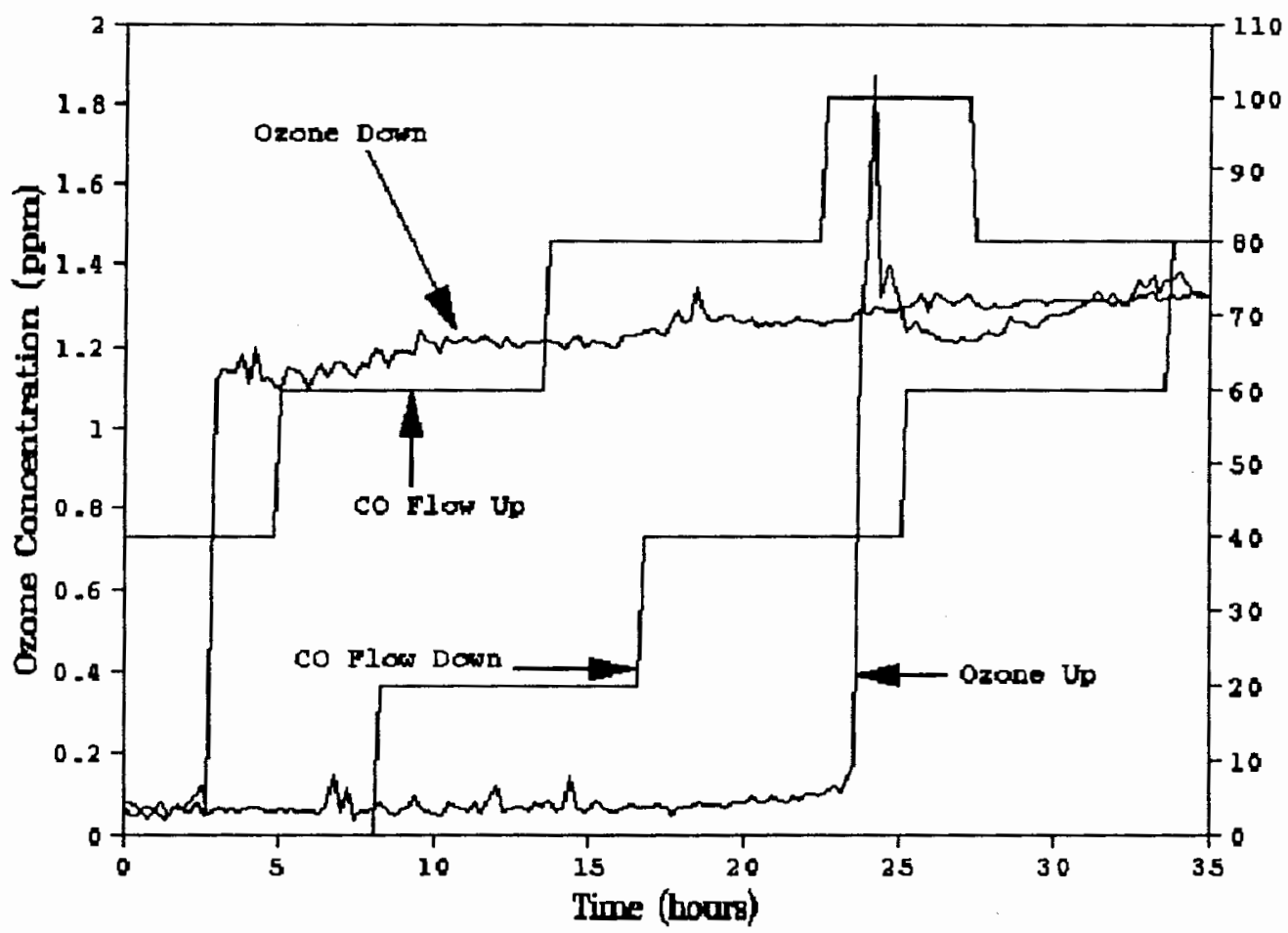

Figure 14. Ozone and Co flow versus time, showing hysteresis. This figure shows the Ozone concentration, and the CO Flow as a function of the path the experiment actually took. The ozone concentration and CO Flow were remapped to show the hysteresis loop formed. The data was reversed in time at the mid-point in the experiment, i.e. at the time value for the middle of the data time was decreased from that point forward till the last point was at zero time. This resulted in the figure shown above. 


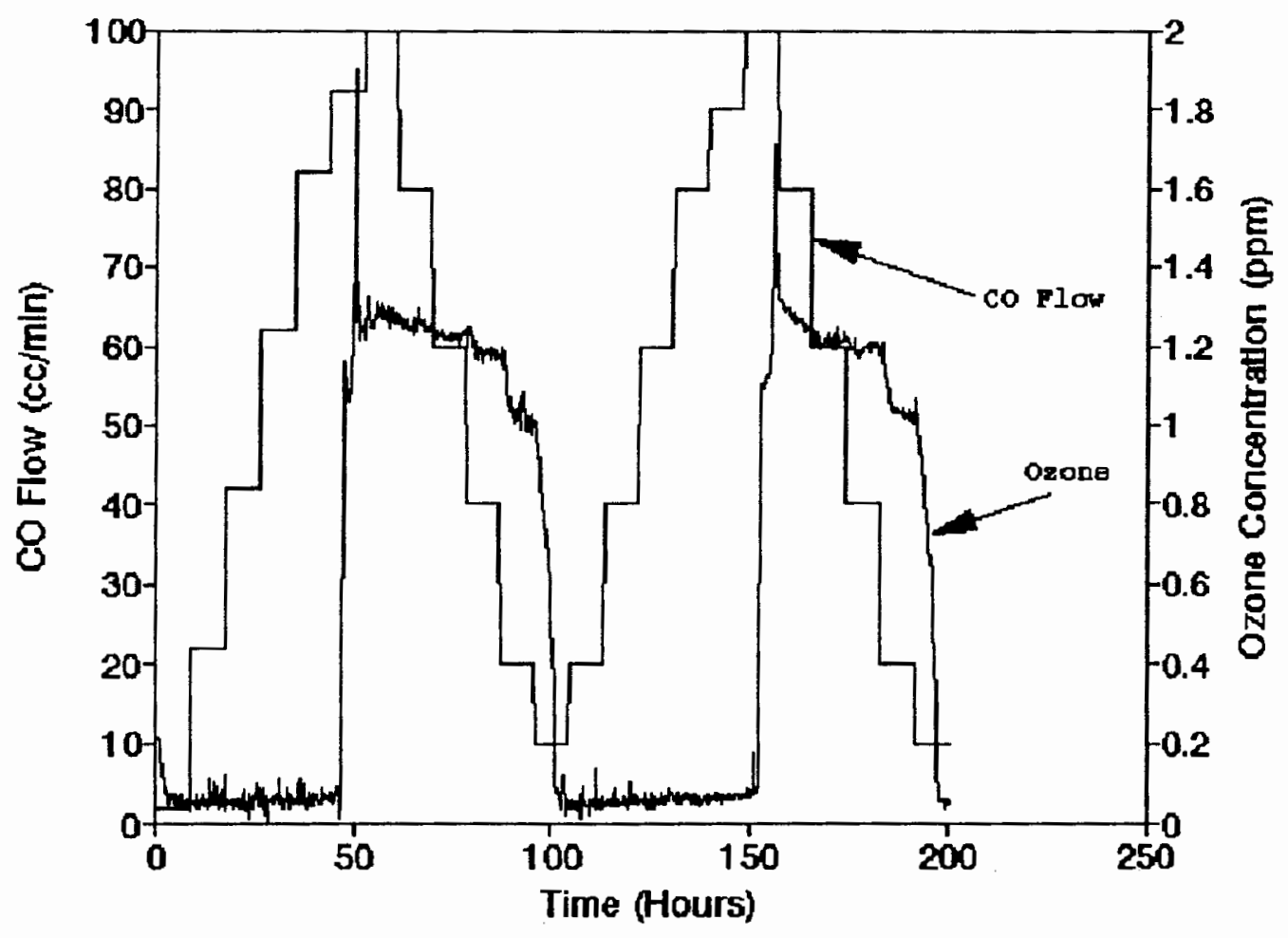

Figure 15. Ozone and CO flow versus time showing reproducability. This figure shows a run for approximately a week of the experiment. The Co flow was stepped to maximum flow, $100 \mathrm{cc} / \mathrm{min}$, then returned to zero flow via computer control. The ozone concentration is seen to go through two periods of maximum concentration, then returning to low values. The inflection points for the increase, and decrease, happen at about similar values of the co flow. 


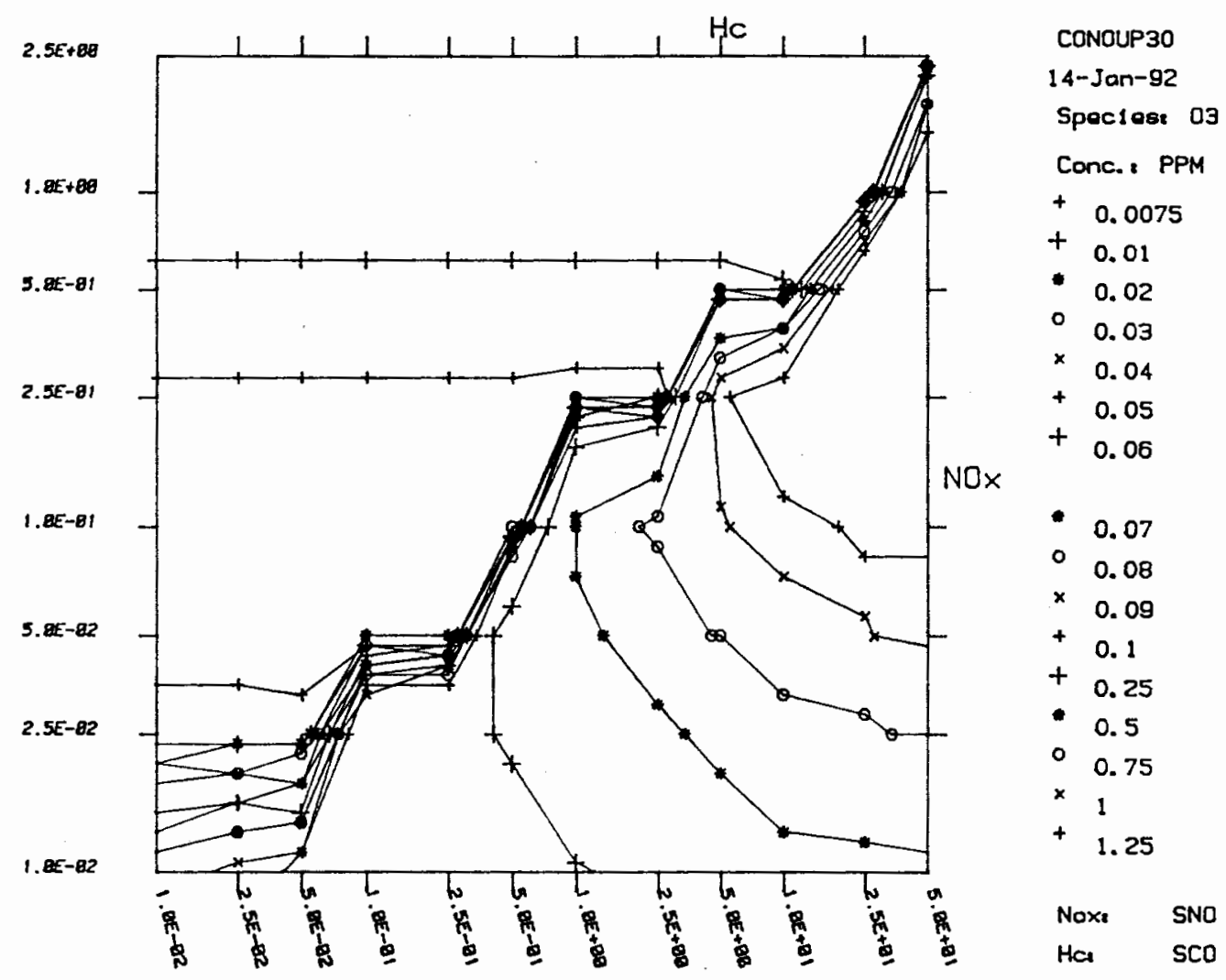

Figure 16. Isopleth for the clean air mechanism forward. source rates are initially low progressing to high values. 


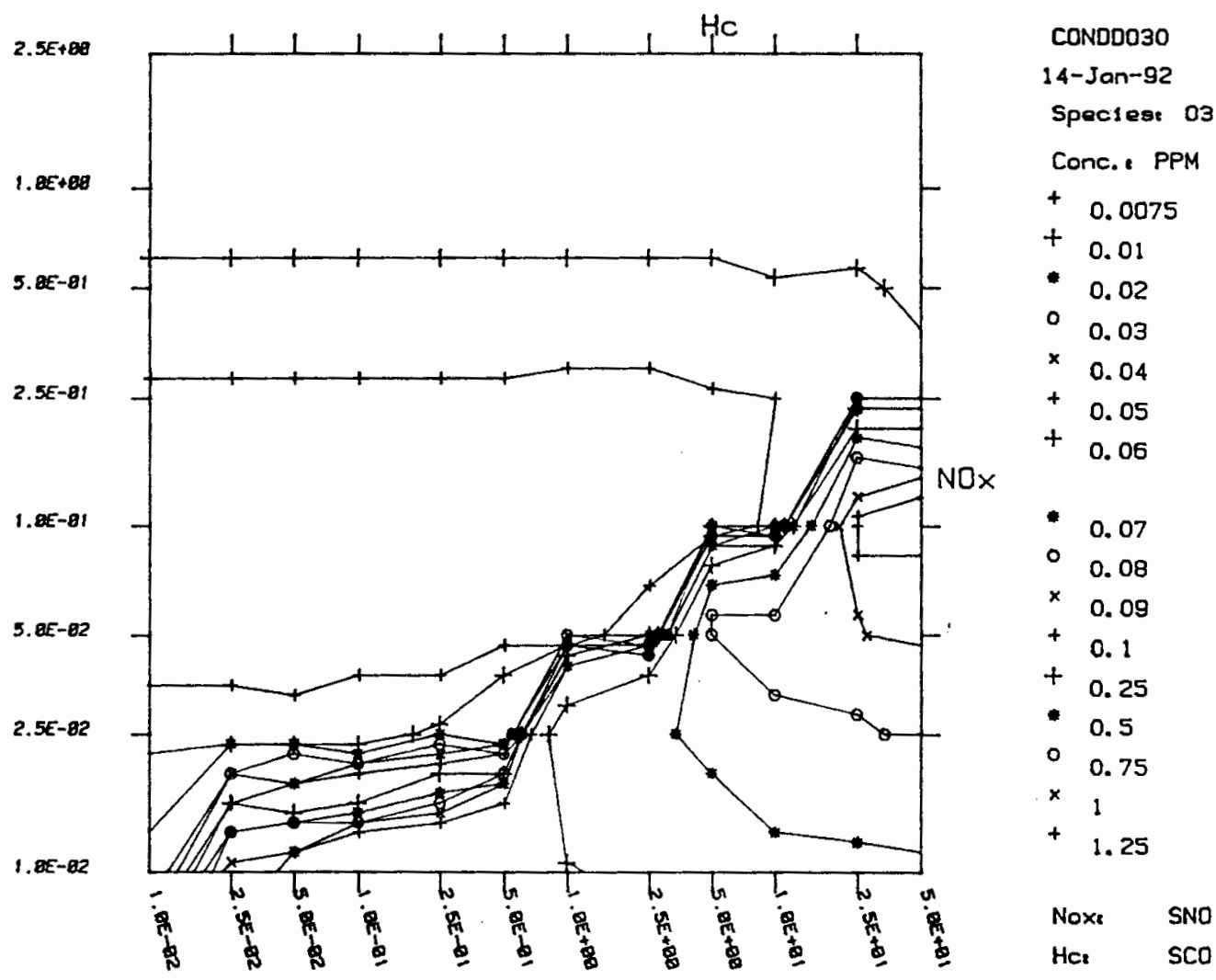

Figure 17. Isopleth for the clean air mechanism reverse. source rates are initially high progressing to low values. 


\section{CHAPTER V}

\section{CONCLUSIONS}

\section{THEORETICAL}

This study of clean air hysteresis did provide many new insights into the possible behavior of atmospheric chemical processes. This method of analyzing the behavior of mechanisms should be considered in any application studying the fate of atmospheric species. The relative ease in which these mechanisms can be analyzed with computers (both theoretically and experimentally) makes this a method to compliment other experimental aspects of gas phase atmospheric chemistry. We are aware of only two previous discussions relating to the modelling of atmospheric mechanisms in the context of the hysteresis effect (Dietz \& White 1984)(Kasting \& Ackerman 1985). The modelling of the mechanism utilized in the experimental section provided a very accurate representation of the chemistry that took place. The parameters predicted by the model were proven to represent the system to a high degree of accuracy. Pitfalls inherent in any theoretical study may be expressed as "what do the solutions actually represent?" This was a problem, 
as the mechanisms grew more complex the physical meaning of the solutions became more obscure. Further developments in the analysis techniques should make these solutions a little less ambiguous.

\section{EXPER IMENTAL}

The experimental study placed a physical significance to the theoretical models. The data gathered with the experimental setup described in chapter four indicate that the hysteresis effect is a real phenomenon. The experimental study also indicates that this could be a more prevalent effect than has been imagined. The hysteresis effect should be considered a part of any study done with atmospheric chemistry. I am aware of no experimental study of the hysteresis effect as it might apply to atmospheric chemistry. A more complete study of this effect, to include hydrocarbons, should provide better insight into the number of systems and conditions that will demonstrate this effect. 
Altshuller, A. P., and McPherson, S. P. (1967).

"spectroscopic Analysis of Aldehydes in the Los Angeles Atmosphere," Journal of the Air Pollution Control Association, 13, 109-111.

Barton, I. J., and Robertson, D. F. (1975): "Measurement of Erythemally Effective Ultraviolet Radiation and Total Ozone Content," Nature, Vol. 258, 68-69.

Beno, Mary F., Jonah, Charles D., and Mulac, William A. (1985). "Rate Constants for the Reaction $\mathrm{OH}+\mathrm{CO}$ as Functions of Temperature and water Concentration," International Journal of Chemical Kinetics, Vol. 17, 1091-1101.

Bufalini, Joseph J., Bufalini, Marijon M., and Walter, Theodore A. (1976). "Ozone Formation Potential of Organic Compounds," Environmental Science and Technology, Vol. 10, No. 9, 908-912.

Clyne, Michael A. (1976). "Destruction of stratospheric Ozone," Nature, Vol. 263, 723-726.

Cox, R. A. (1978). "Trace Gas Photochemistry in the Troposphere," Journal of Photochemistry, Vol. 9, No. 2$3,85-86$.

Crabtree, James H., Holmes, John R., O'Brien, Robert J., Hecht, Thomas A., and Seinfeld, John H. (1973). "Measurement of Ultraviolet Radiation Intensity in Photochemical Smog studies, "Environmental science and Technology, Vol. 7, No. 6, 519-523.

Crutzen, Paul (1973). "A Review of Upper Atmospheric Photochemistry," Canadian Journal of Chemistry, Vol. 52 , 1569-1581.

Darnall, Karen R., Lloyd, Alan C., Winer, Arthur M., Pitts, James M. Jr. (1976). "Reactivity Scale for Atmospheric Hydrocarbons Based on Reaction with Hydroxyl Radical," Environmental Science and Technology, Vol.10, No.7, 692-696. 
Dickinson, Robert E. (1973). "Climatic Effects of stratospheric Chemistry," Canadian Journal of Chemistry, vol. 52, 1616-1624.

Dietz, David, and White, Warren H. (1984). "Does the Photochemistry of the Troposphere admit more than one steady state?," Nature, Vol. 309, 242-244.

Farrow, L. A., Graedel, T. E., and Weber, T. A. (1976). "Kinetic studies of the Photochemistry of the Urban Troposphere," Atmospheric Environment, Vol. 10, 10951116.

Gray, Peter, and Scott, stephen K. (1990). "Chemical Oscillations and Instabilities Non-Linear Chemical Rinetics," Claredon Press, Oxford.

Green, R. G., Wayne, R. P. (1976). "Relative Rate Constants for the Reactions of $O\left({ }^{1} D\right)$ atoms with

fluorochlorocarbons and with $\mathrm{N}_{2} \mathrm{O}, "$ Journal of Photochemistry, 6, 371-374.

Grosjean, Daniel, and McMurry, Peter H. (1985). "Gas and Aerosol Wall Losses in Teflon Film Smog Chambers," Environmental Science and Technology, Vol. 19, No. 12, 1176-1181.

Kasting, J. F., and Ackerman T. P. (1985). "High Atmospheric NOx Levels and Multiple Photochemical steady states," Journal of Atmospheric Chemistry, 3, 321-340.

Khalil, M. A. K., and Rasmussen, R. A. (1990). "Atmospheric Carbon Monoxide: Latitudinal Distribution of Sources," Geophysical Research Letters, Vol. 17, No. 11, 19131916.

Koop, stuart A., and Ogren, Paul J. (1976). "HO 2 Kinetics in simple Systems," Journal of Chemical Education, Vol. 53 , No. 2 , 128-129.

Levine, Joel S. (1985). "The Photochemistry of Atmospheres," Academic Press Inc. (London) Ltd., 39-76.

Levy, Hiram II (1972). "Photochemistry of the Lower Troposphere," Planetary and Space Science, Vol. 20, 919-935.

Logan, J. A., et. al. (1981). "Tropospheric Chemistry: A Global Perspective," Journal of Geophysical Research, Vol. 86, No. C8, 7210-7254. 
London, Julius, and Park, Jae H. (1973). "The Interaction of Ozone Photochemistry and Dynamics in the stratosphere. A Three-dimensional Atmospheric Model," Canadian Journal of Chemistry, Vol. 52, 1599-1609.

Moore, John W., and Pearson, Ralph G. (1981). "Kinetics and Mechanism", Third Edition, John wiley \& Sons, Inc.

Penkett, stuart A. (1991). "Changing Ozone Evidence for a Perturbed Atmosphere," Environmental Science and Technology, Vol. 25, No. 4, 631-635.

Pitts, J. N. Jr., Lloyd, A. C., and Sprung, J. L. (1975) . "Ecology, Energy, and Economics," Chem, Brit, $11,247-$ 256 .

Salem, L. (1976). "Theory of Photochemical Reactions," Science, Vol. 191, 822-829. 


\section{APPENDIX}

\section{COMPUTER PROGRAMS}

100 ON ERROR GOTO 9700

200 CLS : $Z=13: I C=0: A C=1: C O U N T E R=0: S K I P=5: P T O T=0: D E C=0: E 1=0:$

INCREMENTER $=0:$ EXTRA $=0$

300 TIMEPREV=VAL (LEFT\$ (TIME\$, 2))

400 IN $\$=$ "Incrementing" : DE $\$=$ "Decrementing"

500 DIM $P(52): P O=0: P I=6: P T O T=0$

600 INPUT "Enter Desired Voltage for NO controller "ivNO

700 INPUT "Enter Desired Voltage for CO controller "ivCO

800 INPUT "Enter Desired Voltage for 03 controller ";VO3

900 PRINT: PRINT

910 INPUT "Enter a 0 to increment CO or a 1 to decrement CO "; DEC

1000 IF SKIP $<=1$ THEN GOTO 3100 ELSE GOTO 1100

1100 PRINT:INPUT "Do you want to increment CO ";SK\$

1200 IF SK\$="N" OR SK\$="n" THEN SKIP=0:GOTO 1500

1300 IF SK\$="Y" OR SK\$="Y" THEN SKIP=1:GOTO 1500

1400 PRINT "Try again Dude!!!! (Y/N) only!!!":GOTO 1100

1500 INPUT "Do you want to open an Output File? (Y/N) ";OF\$

1600 IF OF $\$=" Y$ " OR OF $\$=" Y$ " THEN OPEN "O",1, "research/dat: 1 "

1700 IF OF $\$=" Y "$ OR OF $\$=" Y$ " THEN WRITE \#1,"Time",

" 03 Conc (ppm)", "CO Voltage"

1750 CLOSE 1

1800 INPUT "Do you want the printer to record ozone Moniter Voltage $(\mathrm{Y} / \mathrm{N})$ : ";AS

1900 IF $A \$=" Y "$ THEN PRTOFF=1:GOTO 2400

2000 IF A\$="Y" THEN PRTOFF=1:GOTO 2400

2100 IF $A \$=" N "$ THEN PRTOFF $=0:$ GOTO 2400

2200 IF $A \$=" n$ " THEN PRTOFF=0:GOTO 2400

2300 PRINT "Invalid responsel!!":GOTO 1800

2400 CLS : OVNO $=\mathrm{VNO} * 50: \mathrm{OVCO}=\mathrm{VCO} * 50: 0 \mathrm{OO} 3=\mathrm{VO} 3 * 50$

$2500 \mathrm{CNO}=0: \mathrm{CO} 3=1: \mathrm{CCO}=2$

2600 OUT CNO,OVNO:OUT CO3,OVO3:OUT CCO,OVCO

2700 PRINT "Voltage sent to NO controller is: "iVNO

2800 PRINT "Voltage sent to the CO controller is: ";VCO

2900 PRINT "Voltage sent to the 03 controller is: ";VO3

3000 IF E1=1 THEN STOP

3100 IF SKIP $=0$ THEN GOTO 3400

3200 EXTRA=INCREMENTER/40

3300 IF EXTRA=1 THEN GOTO 8800 
3400 OUT $6,0: D=I N P(P I): H=I N P(P I): L=I N P(P I)$

3500 OF $=(H * 256+\mathrm{L}) * 5 / 4095$

3600 PRINT $(3,1), "$

3700 OUT PI, $1: D=I N P(P I)$

$3800 \mathrm{H}=\mathrm{INP}(\mathrm{PI}+1)$

$3900 \mathrm{~L}=\operatorname{INP}(\mathrm{PI})$

4000 PRINT "Flow for the NO Controller is: " $i(((\mathrm{~L}+(\mathrm{H} * 256)) * 5 / 4095-\mathrm{OF}) / 5) * 10 ;$ "CC per minute"

4100 OUT $P I, 3: D=I N P(P I)$

$4200 \mathrm{H}=\operatorname{INP}(P I+1)$

$4300 \mathrm{~L}=\mathrm{INP}(\mathrm{PI})$

4400 PRINT "Flow for the co Controller is: " $i(((\mathrm{~L}+(\mathrm{H} * 256)) * 5 / 4095-\mathrm{OF}) / 5) * 100 ; "$ CC per minute"

4500 OUT $P I, 5: D=I N P(P I)$

$4600 \mathrm{H}=\mathrm{INP}(\mathrm{PI}+1)$

4700 L=INP(PI)

4800 PRINT "Flow for the 03 Controller is: " $i(((L+(H * 256)) * 5 / 4095-O F) / 5) * 100 ; "$ CC per minute"

4900 PRINT:PRINT:PRINT

5000 OUT $P I, 7: D=I N P(P I)$

$5100 \mathrm{H}=\operatorname{INP}(\mathrm{PI}+1)$

5200 L=INP (PI)

5300 PRINT "Ozone moniter is reading " i $(\mathrm{L}+(\mathrm{H} * 256)) * 5 / 4095-O F ; "$ Volts ":PRINT

5400 FOR WATCH=1 TO $1500:$ NEXT WATCH

5500 IF PRTOFF=0 THEN PRINT "Printer not recording" ELSE PRINT "Printer On"

5600 PRINT:PRINT "Counter=";COUNTER;" Time is " ; TIME : COUNTER=COUNTER+1

5700 IF DEC $=0$ THEN ID $\$=I N \$$ ELSE ID $=$ DE $\$$

5800 PRINT:IF SKIP=0 THEN PRINT "CO not incrementing" ELSE PRINT "CO ";ID\$;" every 6 hours by $10 \mathrm{cC} / \mathrm{min} "$

5900 IF COUNTER>200 THEN GOTO 6100 ELSE GOTO 6000

6000 GOTO 3100

6100 REM signal loop

6300 POUT $=(\mathrm{L}+(\mathrm{H} * 256)) * 5 / 4095-\mathrm{OF}$

7100 IF POUT<0 THEN GOTO 3100

7200 THOUR $\$=$ LEFT $\$(T I M E \$, 2)$

7300 THOUR=VAL ( THOUR\$)

7400 TMINUTE $\$=$ MID $\$($ TIME $\$, 4,2)$

7500 TMINUTE $=($ VAL $($ TMINUTE $\$)) / 60$

7600 TSECOND $\$=$ RIGHT $($ TIME $\$, 2$ )

7700 TSECOND $=($ VAL $($ TSECOND\$ $)) / 3600$

7800 TIME=THOUR+TMINUTE+TSECOND

7850 OPEN "E", 1, "RESEARCH/DAT: 1 "

7900 WRITE \#1,TIME, POUT, VCO

7950 CLOSE 1

7955 INCREMENTER=INCREMENTER +1

8000 IF PRTOFF=0 THEN GOTO 8700 ELSE GOTO 8100

8100 LPRINT "Ozone moniter is reading: "; POUT; 
" Volts at Time=" ; TIME\$

8200 POUT $=0:$ PTOT $=0$

8300 LPRINT "CO VOLTAGE IS : ";VCO;" AT TIME=";TIME\$

8400 LPRINT "NO VOLTAGE IS: ";VNO;" AT TIME=";TIME\$

8500 FOR XYZ=1 TO $1000:$ NEXT XYZ

8600 COUNTER $=0$

8700 COUNTER $=0:$ GOTO 3100

8800 REM CO Flow Regulator

8900 IF VCO $>=5$ THEN GOTO 9500

9000 IF DEC $=1$ AND VCO $>=1.25$ THEN VCO=VCO- 1 ELSE GOTO 9680

9050 IF DEC $=0$ AND VCO $<=3.5$ THEN VCO=VCO+1 ELSE GOTO 9690

9100 IF VCO $<=0$ THEN GOTO 9650

9200 IF VCO $>5$ THEN VCO $=5$

9205 INCREMENTER $=0$

9400 GOTO 2400

$9500 \mathrm{DEC}=1$

9600 GOTO 9000

$9650 \mathrm{DEC}=0$

9675 GOTO 9000

9680 IF DEC $=1$ THEN VCO=VCO-.5 ELSE GOTO 9050

9685 GOTO 9100

9690 IF $\mathrm{DEC}=0$ THEN $\mathrm{VCO}=\mathrm{VCO}+.5$

9695 GOTO 9100

9700 OVCO $=0$

9800 OVNO $=0$

9900 OVO3 $=0$

10000 PRINT "Error Occurred at ";TIME\$

$10100 \quad \mathrm{E} 1=1$

10200 GOTO 2500

10300 REM Experiment End

10400 CLOSE 1

10500 OUT 0,0

10600 OUT 1,0

10700 OUT 2,0

10800 CLS:PRINT "Experiment ended at ";TIME\$

10900 STOP 